\title{
Comparative Seed Yield Stability of Determinate and Indeterminate RILs of Dolichos Bean (Lablab purpureus L. Sweet) var. lignosus
}

\author{
Chandrakant $^{1 *}$, H.R. Uday Kumar ${ }^{2}$, S. Ramesh ${ }^{1}$, C.M. Keerthi ${ }^{3}$, \\ A. Mohan Rao ${ }^{1}$, M. Byregowda ${ }^{4}$ and Suresh ${ }^{5}$ \\ ${ }^{1}$ Department of Genetics and Plant Breeding, UAS, GKVK, Bengaluru, India \\ ${ }^{2}$ AICRP on Soybean, ZARS, UAS, GKVK, Bengaluru, India \\ ${ }^{3}$ AICRP on Pigeon pea, ZARS, UAS, GKVK, Bengaluru, India \\ ${ }^{4}$ Dean of Student Welfare, UAS, Bengaluru, India \\ ${ }^{5}$ AICRP on small millets, ZARS, VC farm Mandya, India \\ *Corresponding author
}

\section{A B S T R A C T}

\begin{abstract}
Keywords restricting its production only to short-day environments. Determinate photoperiod insensitive varieties enable round-the year-production of dolichos bean. Determinate varieties being short-duration fit into multiple cropping systems leading to sustainable

Determinate,

Indeterminates,

Stability, AMMI,

GGE

Article Info

Accepted:

26 December 2017

Available Online:

10 January 2018 agricultural production. While majority of farmers are in favor of determinate varieties, a few of them still prefer traditional indeterminate photoperiod sensitive land races varieties, as they opine that indeterminates are more stable in performance than determinates. A large number of deteminates and indeterminate RILs belonging to different maturity groups were compared for their performance stability. The study indicated that by and large determinate and indeterminate RILs are comparable for stability of seed yield plant ${ }^{-1}$ in early to medium maturity groups. The results of the present study provide adequate evidence to dispel the notion of certain section of farmers regarding better performance stability of indeterminates than determinates and hence support to breed early to medium duration determinate dolichos bean varieties with performance stability comparable to indeterminate varieties.
\end{abstract}

Dolichos bean has evolved as a short-day photoperiod sensitive indeterminate crop,

\section{Introduction}

Dolichos bean var. lignosus is grown in the tropical regions in Asia, Africa, Australia and America (Fuller, 2003). In India, it is primarily grown in Karnataka and adjoining districts of Tamil Nadu, Andhra Pradesh and Maharashtra (Mahadevu and Byregowda,
2005; Ramesh and Byregowda, 2016). It is grown as a rainfed intercrop with finger millet, maize, and sorghum in southern India. However, due to the availability of a few photoperiod insensitive determinate cultivars (Girish and Byregowda, 2009), dolichos bean is being cultivated as a pure crop in irrigated ecosystems in southern Karnataka and 
adjoining districts of Andhra Pradesh and Tamil Nadu. In Karnataka, dolichos bean is grown in an area of 0.65 lakh hectares with a production of 0.73 lakh $\mathrm{t}$ and contributes nearly 90 per cent of both area and production in India (raithamitra.co.in). It is grown for fresh pods containing immature grains for use as a vegetable.

Dolichos bean has evolved as highly responsive to photoperiod and requires shortdays for switching over from vegetative to reproductive phase and exhibit indeterminate growth habit (Ayyangar and Nambiar, 1935; Shivashankar and Kulkarni, 1989). Most cultivars grown by farmers are photoperiod sensitive (PS) and display indeterminate growth habit (Ayyangar and Nambiar, 1935; Shivashankar and Kulkarni, 1989; Keerthi et al., 2014a). The cultivars with indeterminacy and photoperiod sensitivity are advantageous for subsistence production and consumption of dolichos bean, as it enables harvesting of pods in multiple pickings ensuring continuous availability of pods for a longer time (Keerthi et al., 2014a: Keerthi et al., 2014b; Laxmi et al., 2016). PS indeterminate cultivars accumulate adequate biomass for satisfactory economic product production under variable sowing dates, a common feature in rainfed production environments where dolichos is predominantly grown (Laxmi et al., 2016). However, of late, due to market economy there is increased demand for dolichos bean throughout the year. This is possible only from photoperiod insensitive (PIS) varieties with a determinate growth habit. Determinate varieties enable production of dolichos bean on a commercial scale in a single harvest due to their synchronous flowering and pod bearing ability. Considering the success of breeding for determinate varieties and their wide acceptance and popularity in other comparable legumes such as soybean, cowpea, common bean etc., and even in dolichos bean, the major emphasis of dolichos bean breeding has been to develop PIS determinate varieties with high pod yield. Being predominantly a self-pollinated crop (Harland, 1920; Ayyangar and Nambiar, 1935; Choudhury et al., 1989; Shivashankar and Kulkarni, 1989; Kukade and Tidke, 2014) and non-availability of reliable and economically feasible pollination control system, pure-lines are the only cultivar options in dolichos bean (Ramesh and Byregowda, 2016). However, in a few production environments, farmers are still in favor of PS indeterminate varieties as they opine that indeterminate cultivars are more stable than determinate varieties. Hence, the objective of the present investigation is to compare the performance stability of determinate and indeterminate stabilized RILs within different maturity groups.

\section{Materials and Methods}

The material for the study comprised of two $\mathrm{F}_{10}$ RIL mapping populations derived from HA $4 \times$ CPI 31113 and HA $4 \times$ CPI 60125 belonging to Lablab purpureus var. lignosus. HA 4 is a popular photoperiod insensitive determinate variety, CPI 31113 and CPI 60125 are highly photoperiod sensitive and indeterminate exotic (Uganda) germplasm accessions. HA 4 differs from CPI 31113 and CPI 60125 for dry seed yield plant ${ }^{-1}$ and its component traits such as number of racemes plant $^{-1}$, raceme length, fresh pods raceme ${ }^{-1}$ and fresh pods plant ${ }^{-1}$.

The two crosses HA $4 \times$ CPI 31113 and HA 4 $\times$ CPI 60125 will henceforth be referred to as HACPI 3 and HACPI 6. The seeds of 112 RILs derived from HACPI 6 and 124 RILs derived from HACPI 3 and three check entries [HA 3, HA 4 and kadalavare (KA)] were procured from germplasm unit maintained at All India Co-ordinated Research Project (AICRP) on pigeonpea, University of Agricultural Sciences (UAS), Bengaluru, India. 


\section{Layout of the experiment}

The seedlings of all the RILs and the checks were raised in polythene covers and maintained for 15-20 days for proper rooting. Subsequently, the seedlings of two RIL population and those of the three check entries were transplanted separately to field in an augmented design (Federer, 1961) in six compact blocks during kharif-2016 at the experimental plots of Department of Genetics and Plant Breeding, UAS, Bengaluru. Each block consisted of 18-20 RILs, three checks and two border entries. The seedlings of each entry were transplanted in a single row of 2.5 $\mathrm{m}$ length, with a row spacing of $0.45 \mathrm{~m}$. A basal dose of 25:50:25 Kg ha ${ }^{-1}$ of NPK (nitrogen: phosphorous: potassium) was applied to the experimental plots. Recommended management practices were followed during the crop-growing period to raise a healthy crop.

\section{Sampling of plants and data collection}

In HACPI 6-derived RILs, out of 112 planted, only 109 individuals and in HACPI 3-derived RIL, out of 124 planted, only 117 individuals survived till the maturity. The RILs derived from both HACPI 3 and HACPI 6 segregated for growth habit (determinate and indeterminate). Growth habit of survived RILs was recorded as determinate and indeterminate. Data were also recorded on dry seed yield plant $^{-1}$ as the average weight of the sun-dried seeds harvested from five randomly selected plants in each RIL and check entries following the descriptors (Byregowda et al., 2015).

\section{Comparison between determinate and indeterminate RILs for performance stability}

Based on the common RILs evaluated during kharif-2014, 2015 (unpublished data) and
2016, HACPI 6-derived RILs were classified into two early ( $<50$ days to flowering) and medium (51-60 days to flowering) and those derived from HACPI 3 were classified into medium (51-60 days to flowering) maturity groups. HACPI 3-derived medium maturity group RILs consisted of 7 determinates and 6 indeterminates. HACPI 6-derived early maturity group RILs consisted of 11 determinates and 10 indeterminates; 8 determinates and 9 indeterminates in medium maturity group. Stability of determinate and indeterminate RILs were compared within each maturity group to rule out the possible confounding effects of maturity duration with growth habit. Visual and objective criteria were used to assess comparative seed yield stability performance of determinate and indeterminate RILs. While the visual criterion was based on RIL + RIL $\times$ Year $(G G Y)$ biplot (Yan et al.2000), objective criterion was based on the estimates of AMMI stability value (ASV) (Purchase et al.,2000) and Stability Index (SI) (Farshadfar, 2011). Detection of RIL $\times$ year interaction is a pre-requisite for comparative assessment of performance stability of determinate and indeterminate RILs.

\section{Detection of RIL $\times$ Year Interaction}

The QTs means of each RIL evaluated across three years were subjected to pooled ANOVA to detect RIL $\times$ year interaction. The QTs means of each RIL were also subjected to ANOVA following Additive Main effects and Multiplicative Interaction (AMMI) model (Gouch and Zobel, 1988) to characterize the patterns of RIL $\times$ year interaction. The additive main effects of RIL and years were fitted by univariate ANOVA followed by fitting RIL $\times$ year interaction by principal component (PC) analysis based on the following AMMI II model.

$Y_{i j}=\mu+\mathrm{g}_{\mathrm{i}}+e_{j}+\sum_{k=1}^{n} \lambda_{k} \alpha_{i k} \gamma_{j k}+\varepsilon_{i j}$ 
Where, $Y_{i j}$ is the mean seed yield plant ${ }^{-1}$ of $i^{\text {th }}$ RIL in the $\mathrm{j}^{\text {th }}$ year, $\mu$ is the experimental mean seed yield plant ${ }^{-1}, g_{i}$ and ej are the $i^{\text {th }}$ RIL and $\mathrm{j}^{\text {th }}$ year mean deviation from experimental mean seed yield plant $^{-1}$ values respectively. $\lambda_{\mathrm{k}}$ is the squre root of Eigen value of the $\mathrm{k}^{\text {th }}$ IPC axis, $\alpha_{i k}$ and $\gamma_{j k}$ are the interaction IPC scores for $\mathrm{k}^{\text {th }}$ IPC of the $\mathrm{i}^{\text {th }}$ RIL and $\mathrm{j}^{\text {th }}$ year, respectively and $\varepsilon_{\mathrm{ij}}$ is the residual. The parameters of AMMI II model were estimated using least square principle implemented by GENSTAT software, version 12.

\section{GGY bi-plot analysis}

GGY biplot methodology, which is a combination of AMMI bi-plot and GGY concepts (Yan et al.,2001) was used for visual interpretation of patterns of RIL $\times$ year interaction. The GGY biplot is based on the following model.

$Y_{i j}-\bar{Y}_{j}=\lambda_{1} \alpha_{i 1} \gamma_{j 2}+\lambda_{2} \alpha_{i 2} \gamma_{j 2}+\varepsilon_{i j}$

Where, $Y_{i j}=$ mean seed yield plant ${ }^{-1}$ of $j^{\text {th }}$ RIL in the $\mathrm{j}^{\text {th }}$ year; $Y_{j}=$ mean seed yield plant $^{-1}$ of all the RILs in the $\mathrm{j}^{\text {th }}$ year; $\lambda_{1}$ and $\lambda_{2}$ are the square root of Eigen values of first and second RIL -by-year interaction principal components (IPC) axes, respectively; $\alpha_{\mathrm{i} 1}$ and $\alpha_{\mathrm{i} 2}$ are the scores of the first and second IPC, respectively for the $i^{\text {th }}$ RIL, $\gamma_{j 1}$ and $\gamma_{j 2}$ are the first and second IPCs respectively for $\mathrm{j}^{\text {th }}$ year. GGY biplots were used to evaluate the test years and RILs. While test years were evaluated using discriminativeness and representativeness view of GGY bi-plot, the RILs were evaluated using (1) average year co-ordination (AYC) view based on RIL-focused scaling for ranking of RILs relative to ideal RIL, (2) AYC view based on year-focused scaling for determining performance of RILs vs. their stability patterns and (3) polygon view based on symmetrical scaling for determining which-won-where patterns of RILs with test years (Segherloo et al., 2010).
AMMI stability value (ASV) and Stability Index (SI) estimation

To facilitate an objective method of identifying RILs with high/low stability of seed yield plant $^{-1}$ across years, the AMMI stability value (ASV) was estimated (Purchase et al., 2000).

$A S V=\sqrt{\left[\frac{S S \text { IPC } 1}{\text { SS IPC } 2}(\text { IPC1 score })\right]^{2}+(\text { IPC2 score })^{2}}$

Where, SSIPC 1 and SSIPC 2 are sum of squares attributable to first two IPC's. Conceptually, ASV is the distance from zero in a two dimensional scatter gram of IPCA 1 vs IPCA 2 scores (Purchase et al., 2000). Since the IPCA 1 score generally contributes proportionately more to GYI, it was weighed by the proportional difference between IPCA 1 and IPCA 2 scores in order to compensate for the relative contribution of IPCA 1 and IPCA 2 scores to total GYI sum of squares. Higher magnitude of estimates of ASV indicates higher stability, while lower magnitude of ASV indicates lower stability (Purchase et al., 2000). To facilitate simultaneous selection of RILs for seed yield plant $^{-1}$ and stability (stability in the present study) index (SI) which incorporates both mean seed yield plant ${ }^{-1}$ and stability in a single criterion (Farshadfar, 2011) was estimated as $\mathrm{SI}=\mathrm{RASV}+\mathrm{RY}$ where, RASV is rank of the RILs based on ASV and RY is the rank of RIL based on seed yield plant ${ }^{-1}$ over three years. The RILs with low SI were regarded as those with high seed yield plant ${ }^{-1}$ and high stability.

\section{Results and Discussion}

\section{Detection of RIL $\times$ year interaction}

Detection of RIL $\times$ year interaction is a prerequisite for investigating patterns of stability of RILs across years. This is because, absence 
of RIL $\times$ year interaction suggests stability of test RILs across years, while significant RIL $\times$ year interaction indicate differential performance of RILs.

\section{Pooled ANOVA}

The total variation was partitioned into sources attributable to RILs, years, RIL $\times$ year interaction and pooled error. Mean squares attributable to RILs, year and RIL $\times$ year interaction were highly significant for seed yield plant $^{-1}$ in medium duration RILs derived from HACPI 3 (Table 1). Mean squares attributable to RILs, years and RIL $\times$ year interaction were highly significant for seed yield plant $^{-1}$ both in early and medium duration RILs derived from HACPI 6 . Significant mean squares suggested substantial variability among the RILs for seed yield plant $^{-1}$ and thus justified the selection of RILs for the study. Significant mean squares attributable to years suggested considerable ability of the environment prevailed during the years to discriminate the RILs for seed yield plant $^{-1}$. However, significant mean squares attributable to RIL $\times$ year interaction suggested differential performance of the RILs in the test years (Table 1).

\section{AMMI ANOVA}

In medium duration RILs derived from HACPI 3, the main effects of RILs contributed more towards total variability of the RILs than those of RIL $\times$ year interaction and years for seed yield plant ${ }^{-1}$ (Table 2a). Years contributed least to the variability of RILs for dry seed yield plant $^{-1}$. In both early and medium duration RILs derived from HACPI 6, the per cent variance attributable to RIL $\times$ year interaction towards total variability of the RIL was higher than that attributable to main effects of RIL and years for seed yield plant $^{-1}$ (Table 2b). By and large, the ANOVA clearly suggested least contribution of years per se towards the variability of RILs for seed yield plant $^{-1}$. Significant RIL $\times$ year interaction justifies further analysis of patterns of stability of RILs across years and identifies those which are stable across years within maturity groups. Further, relative stability of determinate $v s$. indeterminate RILs within each maturity group is discussed in the following sections.

\section{AMMI Stability Value (ASV)}

The estimate of ASV is a useful parameter for objective assessment of stability of the RILs. Lower the magnitude of ASV, higher is the stability of the RILs. In the present study, lower magnitude of ASV estimates indicate better stability of most of the medium duration indeterminate RILs derived from HACPI 3 (barring few exceptions; RIL 164) than those of determinate RILs for seed yield plant $^{-1}$ (Table 3a and 3b). However, HACPI 6derived both early and medium duration determinate and indeterminate RILs were comparable for their stability for seed yield plant $^{-1}$ (Table $3 \mathrm{~b}$ and $3 \mathrm{c}$ ).

\section{Stability Index (SI)}

The estimate of SI is another useful parameter for objective assessment of stability of the genotypes based on both mean seed yield and stability. Low magnitude of SI indicates high stability and high performance of the genotypes. In the present study, lower magnitude of estimates of SI indicated (Table 3a), HACPI-3 derived medium duration indeterminate RILs (barring an exception; RIL 164 and RIL 73) than determinate RIL for seed yield plant ${ }^{-1}$. However, indeterminate RILs were not the best performers for dry seed yield plant ${ }^{-1}$. Keerthi et al., (2014a) have also reported that best yielders were not stable across different sowing date environments in dolichos bean. Such negative relationship between performance levels and 
stability/adaptability could be attributed to the possible involvement of different sets of genes controlling per se performance and stability (Caligari and Mather, 1975) and trade-offs between performance and stability (Ludlow and Muchow, 1990). The determinate RILs 124 and RIL 141 with a fairly high dry seed yield plant $^{-1}$ and reasonably good stability could be extensively used in breeding dolichos bean pure-line varieties with high stability and high productivity. Such highly stable varieties are expected to contribute to sustainable dolichos bean production. Also, breeding varieties with high yield and high stability is essential for sustained economic returns to the farmers and hence maintain competitiveness of dolichos bean (which is largely underutilized) with other crops. Both determinate and indeterminate HACPI 6derived early and medium RILs were comparable for their stability for seed yield plant $^{-1}$ (Table $3 \mathrm{~b}$ and $3 \mathrm{c}$ ).

Both early and medium duration HACPI 6derived indeterminate RILs were more stable than determinate RILs for seed yield plant $^{-1}$ as suggested by lower magnitude of estimates of both ASV and SI.

\section{GGY bi-plot analysis of RIL $\times$ year interaction patterns}

Differences in RIL stability and adaptability to environments (years in the present study) can be qualitatively assessed using the biplot graphical representation that scatters the genotypes according to their interaction principal component (IPC) scores (Vita, 2010). Yan et al., (2000) proposed a standard biplot of genotype (G) + genotype $\times$ environment (GE) based on a SREG (sites regression) model referred to GGE biplot. It is a multivariate analytical tool that graphically displays interaction between each genotype and each environment in a two-dimensional biplot. It allows evaluation of environments (years in the present study) and genotypes as
(RILs in the present study). Environment represented by years were evaluated using discriminativeness and representativeness view of GGY biplot, while the RILs were evaluated using (1) AYC view of GGY biplot based on RIL-focused scaling for ranking of RILs relative to ideal RIL, (2) AYC view of GGY biplot based on year-focused scaling for determining mean performance of the RILs $v s$. their stability patterns and (3) polygon view of GGY biplot based on symmetrical scaling for determining 'which-won-where' patterns of RILs with test years.

\section{Environment (represented by years) evaluation}

\section{Discriminating ability and representativeness of years}

Assessment of discriminating and representativeness of test years is based on the length of year vectors, and the angle between the test year vectors and average year coordination (AYC) in the GGY bi-plot. The lines that connect the test year points to the origin of GGY bi-plot is referred to as environment vectors. A single-arrowed line (ray) passing through the origin of the bi-plot and the average of the 3 years is referred as AYC. The average years' environment is represented by the small circle at the end of the arrow (Yan and Tinker, 2006). Shorter the year vectors, lower is the discriminating ability of the year; longer the vector, higher is the discriminating ability of the year. A test year that has a smaller angle with AYC is more representative of test years than the ones with wider angles. The cosine of the angle between the vectors of two years approximates the correlation between them. While acute angle between the vectors of test years indicate positive correlation or similarity between them, obtuse and right angles indicate negative correlation or dissimilarity, and poor relationship, respectively between the test years. 
Table.1 Pooled ANOVA of HACPI 3 and HACPI 6-derived RILs evaluated over three years for seed yield plant ${ }^{-1}(\mathrm{~g})$

\begin{tabular}{|l|c|c|c|c|c|c|}
\hline & \multicolumn{2}{|c|}{ HACPI 3- derived RILs } & \multicolumn{4}{|c|}{ HACPI 6- derived RILs } \\
\hline $\begin{array}{l}\text { Sources of } \\
\text { variation }\end{array}$ & $\begin{array}{c}\text { Degrees } \\
\text { of } \\
\text { freedom }\end{array}$ & $\begin{array}{l}\text { Mean sum } \\
\text { of squares }\end{array}$ & $\begin{array}{c}\text { Early duration } \\
\text { Degrees } \\
\text { of } \\
\text { freedom }\end{array}$ & $\begin{array}{l}\text { Mean sum } \\
\text { of squares }\end{array}$ & $\begin{array}{c}\text { Megrees } \\
\text { of } \\
\text { freedom }\end{array}$ & $\begin{array}{l}\text { Mean sum } \\
\text { of squares }\end{array}$ \\
\hline RIL (G) & 12 & $184.92 * *$ & 20 & $87.59 * *$ & 16 & $99.76 * *$ \\
\hline Years (Y) & 02 & $09.19 * *$ & 02 & $549.51 * *$ & 02 & $1644.51 * *$ \\
\hline G $\times$ Y & 24 & $51.43 * *$ & 40 & $68.75 * *$ & 32 & $120.78 *$ \\
\hline Pooled error & 38 & 00.41 & 62 & 00.17 & 50 & 00.20 \\
\hline (e) & & & & & & \\
\hline
\end{tabular}

** Significant @ P=0.01

Table.2a AMMI ANOVA of HACPI 3- derived medium duration RILs for seed yield plant $^{-1}(\mathrm{~g})$

\begin{tabular}{|c|c|c|c|c|c|}
\hline $\begin{array}{c}\text { Source of } \\
\text { Variation }\end{array}$ & $\begin{array}{l}\text { Degrees of } \\
\text { freedom }\end{array}$ & $\begin{array}{l}\text { Mean sum of } \\
\text { squares }\end{array}$ & F statistic & P $\geq \mathbf{F}$ & \% variation \\
\hline RIL (G) & 12 & 184.92 & 433.22 & 0.0000 & 63.59 \\
\hline Years (Y) & 02 & 09.19 & 14.12 & 0.0000 & 00.51 \\
\hline G X Y & 24 & 51.43 & 120.49 & 0.0000 & 35.36 \\
\hline IPCA 1 & 13 & 71.56 & 167.65 & 0.0000 & 26.66 \\
\hline IPCA 2 & 11 & 27.64 & 64.74 & 0.0000 & 08.71 \\
\hline Residuals & - & & & & \\
\hline Error & 36 & 00.43 & & & \\
\hline
\end{tabular}

Table.2b AMMI ANOVA of HACPI 6-derived early and medium duration RILs for seed yield $\operatorname{plant}^{-1}(\mathrm{~g})$

\begin{tabular}{|c|c|c|c|c|c|c|c|c|c|c|}
\hline \multirow[t]{2}{*}{$\begin{array}{l}\text { Source of } \\
\text { Variation }\end{array}$} & \multicolumn{2}{|c|}{$\begin{array}{l}\text { Degrees of } \\
\text { Freedom }\end{array}$} & \multicolumn{2}{|c|}{$\begin{array}{l}\text { Mean sum of } \\
\text { Squares }\end{array}$} & \multicolumn{2}{|c|}{ F statistic } & \multicolumn{2}{|c|}{$\mathbf{P} \geq \mathbf{F}$} & \multicolumn{2}{|c|}{$\%$ variation } \\
\hline & Early & Mediun & Early & Medium & Early & Medium & Early & Medium & Early & Medium \\
\hline RIL (G) & 20 & 16 & 87.60 & 99.80 & 489.70 & 488.43 & 0.000 & 0.000 & 31.21 & 18.21 \\
\hline Years (Y) & 02 & 02 & 549.50 & 1644.60 & 64032.72 & 6942.48 & 0.000 & 0.000 & 19.58 & 37.54 \\
\hline $\mathbf{G} \times \mathbf{Y}$ & 40 & 32 & 68.70 & 120.80 & 384.36 & 591.37 & 0.000 & 0.000 & 49.00 & 44.11 \\
\hline IPCA 1 & 21 & 17 & 122.20 & 211.90 & 683.43 & 1037.32 & 0.000 & 0.000 & 45.74 & 41.11 \\
\hline IPCA 2 & 19 & 15 & 09.60 & 17.60 & 53.82 & 85.95 & 0.000 & 0.000 & 03.26 & 03.00 \\
\hline Residuals & - & - & - & - & & & & & & \\
\hline Error & 60 & 48 & 00.20 & 00.20 & & & & & & \\
\hline
\end{tabular}


Table.3a Estimates of IPC scores and parameters to assess stability of HACPI 3-derived medium duration RILs for seed yield plant ${ }^{-1}(\mathrm{~g})$

\begin{tabular}{|c|c|c|c|c|c|c|c|c|}
\hline Genotype: & Mean & Rank & IPC 1 & IPC 2 & ASV & Rank & SI & Rank \\
\hline \multicolumn{9}{|c|}{ Determinates } \\
\hline RIL 10 & 11.61 & 4 & -0.83 & -0.93 & 2.70 & 9 & 13 & 5 \\
\hline RIL 124 & 23.31 & 12 & 0.27 & 0.11 & 0.83 & 2 & 14 & 6 \\
\hline RIL 125 & 22.51 & 11 & 0.82 & 0.98 & 2.69 & 7 & 18 & 10 \\
\hline RIL 14 & 15.03 & 8 & 0.73 & -1.92 & 2.94 & 11 & 19 & 11 \\
\hline RIL 141 & 23.50 & 13 & 0.45 & 1.32 & 1.90 & 4 & 17 & 8 \\
\hline RIL 163 & 17.42 & 10 & 1.76 & 1.15 & 5.50 & 12 & 22 & 12 \\
\hline RIL 172 & 12.82 & 7 & 0.91 & -0.10 & 2.78 & 10 & 17 & 8 \\
\hline Mean & 18.02 & & & & & & & \\
\hline $\mathrm{SE} \pm$ & 01.92 & & & & & & & \\
\hline \multicolumn{9}{|c|}{ Indeterminates } \\
\hline RIL 157 & 08.61 & 2 & -0.12 & -0.93 & 0.99 & 3 & 5 & 1 \\
\hline RIL 164 & 15.83 & 9 & -3.73 & 1.12 & 11.45 & 13 & 22 & 12 \\
\hline RIL 181 & 11.92 & 5 & 0.19 & -0.35 & 0.69 & 1 & 6 & 2 \\
\hline RIL 54 & 09.80 & 3 & -0.66 & -0.22 & 2.02 & 5 & 8 & 4 \\
\hline RIL 73 & 12.20 & 6 & 0.85 & 0.74 & 2.69 & 8 & 14 & 6 \\
\hline RIL 09 & 06.93 & 1 & -0.65 & -0.96 & 2.20 & 6 & 7 & 3 \\
\hline Mean & 10.88 & & & & & & & \\
\hline SE \pm & 01.28 & & & & & & & \\
\hline
\end{tabular}

Table.5 Mean performance $v s$. stability of RILs for seed yield plant

\begin{tabular}{|c|c|c|c|c|c|c|c|}
\hline \multirow{3}{*}{$\begin{array}{l}\text { Sl. } \\
\text { no }\end{array}$} & & \multirow{2}{*}{\multicolumn{2}{|c|}{$\begin{array}{c}\text { HA CPI } 3 \\
\text { Medium maturity }\end{array}$}} & \multicolumn{4}{|c|}{ НАСРI 6} \\
\hline & & & & \multicolumn{2}{|c|}{ Early maturity } & \multicolumn{2}{|c|}{ Medium maturity } \\
\hline & & $\mathrm{D}$ & ID & $\mathrm{D}$ & ID & $\mathrm{D}$ & ID \\
\hline 1 & $\begin{array}{l}\text { High mean and } \\
\text { high stability }\end{array}$ & $\begin{array}{l}\text { RIL } 141 \\
\text { RIL } 124 \\
\text { RIL } 125\end{array}$ & - & - & - & RIL 201 & - \\
\hline 2 & $\begin{array}{l}\text { High mean and } \\
\text { less stability }\end{array}$ & - & - & - & RIL 269 & - & RIL 281 \\
\hline 3 & $\begin{array}{l}\text { Low mean and } \\
\text { high stability }\end{array}$ & RIL 10 & $\begin{array}{c}\text { RIL 9 } \\
\text { RIL } 157 \\
\text { RIL 54 } \\
\text { RIL 181 }\end{array}$ & $\begin{array}{l}\text { RIL } 190 \\
\text { RIL } 219\end{array}$ & $\begin{array}{l}\text { RIL } 268 \\
\text { RIL } 354 \\
\text { RIL } 350 \\
\text { RIL } 344 \\
\text { RIL } 346\end{array}$ & $\begin{array}{l}\text { RIL } 253 \\
\text { RIL } 216 \\
\text { RIL } 225\end{array}$ & $\begin{array}{l}\text { RIL } 319 \\
\text { RIL } 307 \\
\text { RIL } 317 \\
\text { RIL } 329\end{array}$ \\
\hline 4 & $\begin{array}{l}\text { Low mean and } \\
\text { less stability }\end{array}$ & RIL 163 & RIL 164 & - & $\begin{array}{l}\text { RIL } 363 \\
\text { RIL } 248\end{array}$ & RIL 251 & $\begin{array}{l}\text { RIL } 352 \\
\text { RIL } 321\end{array}$ \\
\hline
\end{tabular}


Table.3b Estimates of IPC scores and parameters to assess stability of HACPI 6-derived early duration RILs for seed yield plant ${ }^{-1}(\mathrm{~g})$

\begin{tabular}{|c|c|c|c|c|c|c|c|c|}
\hline Genotypes & Mean & Rank & IPC 1 & IPC 2 & ASV & Rank & SI & Rank \\
\hline \multicolumn{9}{|c|}{ Determinates } \\
\hline RIL 188 & 13.71 & 17 & 0.14 & 0.67 & 02.11 & 4 & 21 & 10 \\
\hline RIL 190 & 14.47 & 19 & -1.26 & -0.60 & 17.69 & 19 & 38 & 19 \\
\hline RIL 195 & 12.77 & 16 & 0.14 & -0.95 & 02.23 & 6 & 22 & 13 \\
\hline RIL 205 & 08.91 & 8 & 0.61 & 1.26 & 08.66 & 11 & 19 & 9 \\
\hline RIL 211 & 11.22 & 13 & 0.33 & 0.20 & 04.68 & 8 & 21 & 10 \\
\hline RIL 214 & 08.88 & 7 & 0.77 & -0.27 & 10.75 & 14 & 21 & 10 \\
\hline RIL 219 & 08.22 & 6 & -0.21 & 0.41 & 02.91 & 7 & 13 & 5 \\
\hline RIL 221 & 13.73 & 18 & 0.86 & 0.27 & 12.02 & 15 & 33 & 18 \\
\hline RIL 231 & 11.82 & 14 & -0.06 & -0.34 & 00.93 & 3 & 17 & 7 \\
\hline RIL 248 & 12.18 & 15 & 0.98 & -1.95 & 13.94 & 17 & 32 & 17 \\
\hline RIL 254 & 10.14 & 11 & 0.68 & 0.03 & 09.58 & 12 & 23 & 15 \\
\hline Mean & 11.45 & & & & & & & \\
\hline $\mathrm{SE} \pm$ & 00.65 & & & & & & & \\
\hline \multicolumn{9}{|c|}{ Indeterminates } \\
\hline RIL 241 & 07.21 & 4 & 1.13 & -0.14 & 15.89 & 18 & 22 & 13 \\
\hline RIL 268 & 09.02 & 9 & 0.00 & -0.28 & 00.28 & 1 & 10 & 1 \\
\hline RIL 269 & 20.76 & 21 & -4.57 & -0.22 & 64.12 & 21 & 42 & 21 \\
\hline RIL 290 & 10.42 & 12 & 0.74 & 0.61 & 10.42 & 13 & 25 & 16 \\
\hline RIL 335 & 04.68 & 1 & 0.89 & 0.06 & 12.51 & 16 & 17 & 7 \\
\hline RIL 344 & 06.79 & 3 & 0.62 & 0.03 & 08.63 & 10 & 13 & 5 \\
\hline RIL 346 & 06.36 & 2 & 0.59 & -0.41 & 08.34 & 9 & 11 & 3 \\
\hline RIL 350 & 07.42 & 5 & 0.14 & 1.06 & 02.18 & 5 & 10 & 1 \\
\hline RIL 354 & 09.49 & 10 & 0.05 & 0.21 & 00.71 & 2 & 12 & 4 \\
\hline RIL 363 & 16.99 & 20 & -2.58 & 0.34 & 36.14 & 20 & 40 & 20 \\
\hline Mean & 09.91 & & & & & & & \\
\hline $\mathrm{SE} \pm$ & 01.60 & & & & & & & \\
\hline
\end{tabular}


Table.3c Estimates of IPC scores and parameters to assess stability of HACPI 6-derived medium duration RILs for seed yield plant $^{-1}(\mathrm{~g})$

\begin{tabular}{|c|c|c|c|c|c|c|c|c|}
\hline Genotypes & Mean & Rank & IPC 1 & IPC 2 & ASV & Rank & SI & Rank \\
\hline \multicolumn{9}{|c|}{ Determinates } \\
\hline RIL 201 & 18.11 & 16 & -0.06 & -1.45 & 01.64 & 1 & 17 & 8 \\
\hline RIL 202 & 17.97 & 15 & -2.08 & 1.28 & 28.51 & 13 & 28 & 14 \\
\hline RIL 216 & 13.87 & 10 & -0.90 & 0.41 & 12.31 & 6 & 16 & 6 \\
\hline RIL 225 & 10.59 & 7 & 1.36 & 1.12 & 18.63 & 10 & 17 & 8 \\
\hline RIL 227 & 09.39 & 4 & 1.80 & 0.48 & 24.65 & 12 & 16 & 6 \\
\hline RIL 232 & 16.72 & 12 & -2.29 & -0.04 & 31.42 & 16 & 28 & 14 \\
\hline RIL 251 & 10.62 & 8 & 2.17 & -0.15 & 29.76 & 14 & 22 & 13 \\
\hline RIL 253 & 17.01 & 13 & -1.01 & -0.04 & 13.88 & 7 & 20 & 12 \\
\hline Mean & 14.28 & & & & & & & \\
\hline $\mathrm{SE} \pm$ & 01.28 & & & & & & & \\
\hline \multicolumn{9}{|c|}{ Indeterminates } \\
\hline RIL 279 & 07.16 & 2 & 0.66 & 0.18 & 08.98 & 4 & 6 & 1 \\
\hline RIL 281 & 18.83 & 17 & -3.07 & -0.53 & 42.05 & 17 & 34 & 17 \\
\hline RIL 307 & 06.70 & 1 & 0.79 & 0.01 & 10.86 & 5 & 6 & 1 \\
\hline RIL 317 & 08.98 & 3 & 1.35 & 1.21 & 18.55 & 9 & 12 & 4 \\
\hline RIL 319 & 09.80 & 5 & 0.28 & 0.50 & 03.89 & 2 & 7 & 3 \\
\hline RIL 321 & 13.89 & 11 & 1.07 & -1.53 & 14.69 & 8 & 19 & 11 \\
\hline RIL 329 & 13.29 & 9 & 0.58 & 0.12 & 08.00 & 3 & 12 & 4 \\
\hline RIL 332 & 17.35 & 14 & -2.21 & -0.33 & 30.33 & 15 & 29 & 16 \\
\hline RIL 352 & 10.53 & 6 & 1.56 & -1.25 & 21.43 & 11 & 17 & 8 \\
\hline Mean & 11.83 & & & & & & & \\
\hline $\mathrm{SE} \pm$ & 01.43 & & & & & & & \\
\hline
\end{tabular}

Table.4 Discriminativeness and representativeness of environments represented by years of evaluation of RILs for seed yield plant ${ }^{-1}$

\begin{tabular}{|c|c|c|c|c|}
\hline \multirow{2}{*}{$\begin{array}{l}\text { Sl. } \\
\text { No. }\end{array}$} & & \multirow{2}{*}{$\begin{array}{l}\text { HACPI } 3 \\
\text { Medium }\end{array}$} & \multicolumn{2}{|c|}{ HACPI 6} \\
\hline & & & Early & Medium \\
\hline 1 & $\begin{array}{l}\text { Discriminative } \\
\text { representative }(\mathrm{R})\end{array}$ & - & - & - \\
\hline 2 & $\begin{array}{l}\text { Discriminative (D) but } \\
\text { non-representative (NR) }\end{array}$ & $\begin{array}{l}\text { K-2014 and } \\
\text { K-2016 }\end{array}$ & K-2016 & K-2016 \\
\hline 3 & $\begin{array}{l}\text { Non-discriminative (ND) but } \\
\text { representative (R) }\end{array}$ & K-2015 & K-2015 & K-2015 \\
\hline 4 & $\begin{array}{l}\text { Non-discriminative (ND) and } \\
\text { non-representative (NR) }\end{array}$ & - & - & K-2014 \\
\hline
\end{tabular}


Fig.1a Discriminativeness vs. representativeness view of GGY bi-plot for seed yield plant ${ }^{-1}$ in medium duration (51-60 days to flowering) RILs derived from HACPI 3

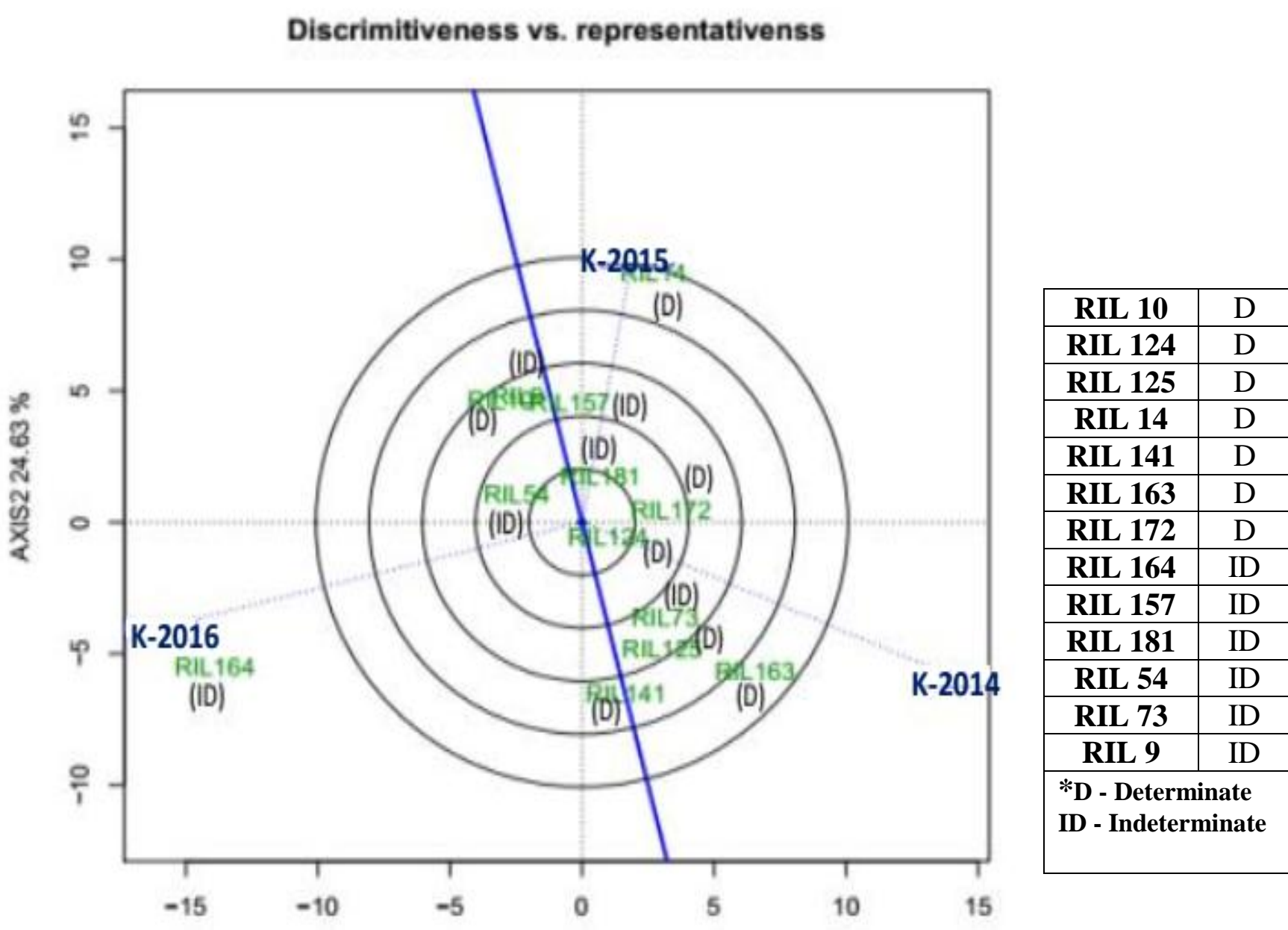

AXIS1 $75.37 \%$ 
Fig.1b Discriminativeness vs. representativeness view of GGY bi-plot for seed yield plant ${ }^{-1}$ in early duration ( $<50$ days to flowering) RILs derived from HACPI 6

Discrimitiveness vs. representativenss

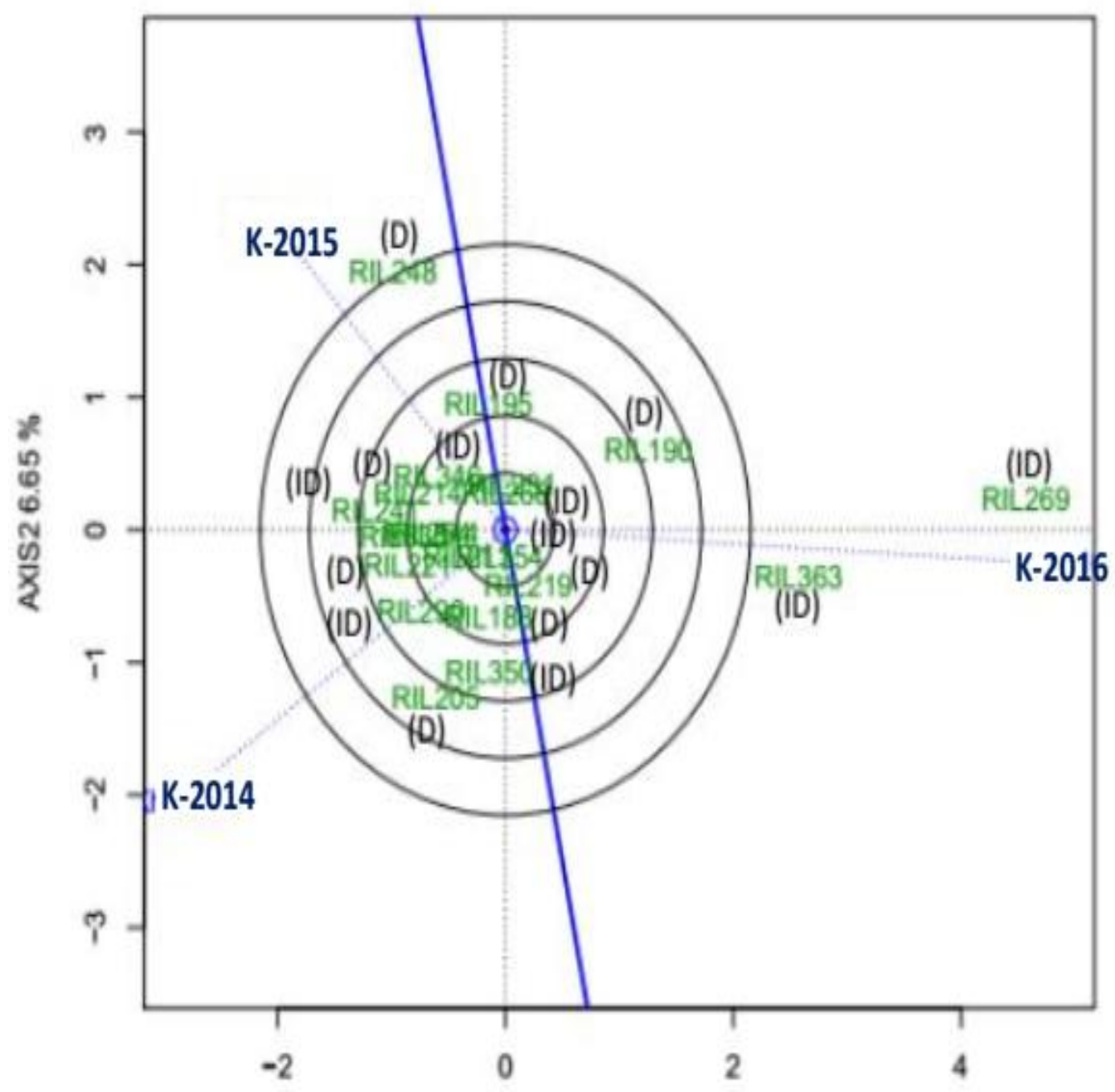

\begin{tabular}{|c|c|}
\hline RIL 188 & D \\
\hline RIL 190 & D \\
\hline RIL 195 & D \\
\hline RIL 205 & D \\
\hline RIL 211 & D \\
\hline RIL 214 & D \\
\hline RIL 219 & D \\
\hline RIL 221 & D \\
\hline RIL 231 & D \\
\hline RIL 248 & D \\
\hline RIL 254 & D \\
\hline RIL 241 & ID \\
\hline RIL 268 & ID \\
\hline RIL 269 & ID \\
\hline RIL 290 & ID \\
\hline RIL 335 & ID \\
\hline RIL 344 & ID \\
\hline RIL 346 & ID \\
\hline RIL 350 & ID \\
\hline RIL 354 & ID \\
\hline RIL 363 & ID \\
\hline *D - Determinate \\
ID - Indeterminate \\
\hline
\end{tabular}

AXIS1 $93.35 \%$ 
Fig.1c Discriminativeness vs. representativeness view of GGY bi-plot for seed yield plant $^{-1}$ in medium duration (51-60 days to flowering) RILs derived from HACPI 6

\section{Discrimitiveness vs. representativenss}

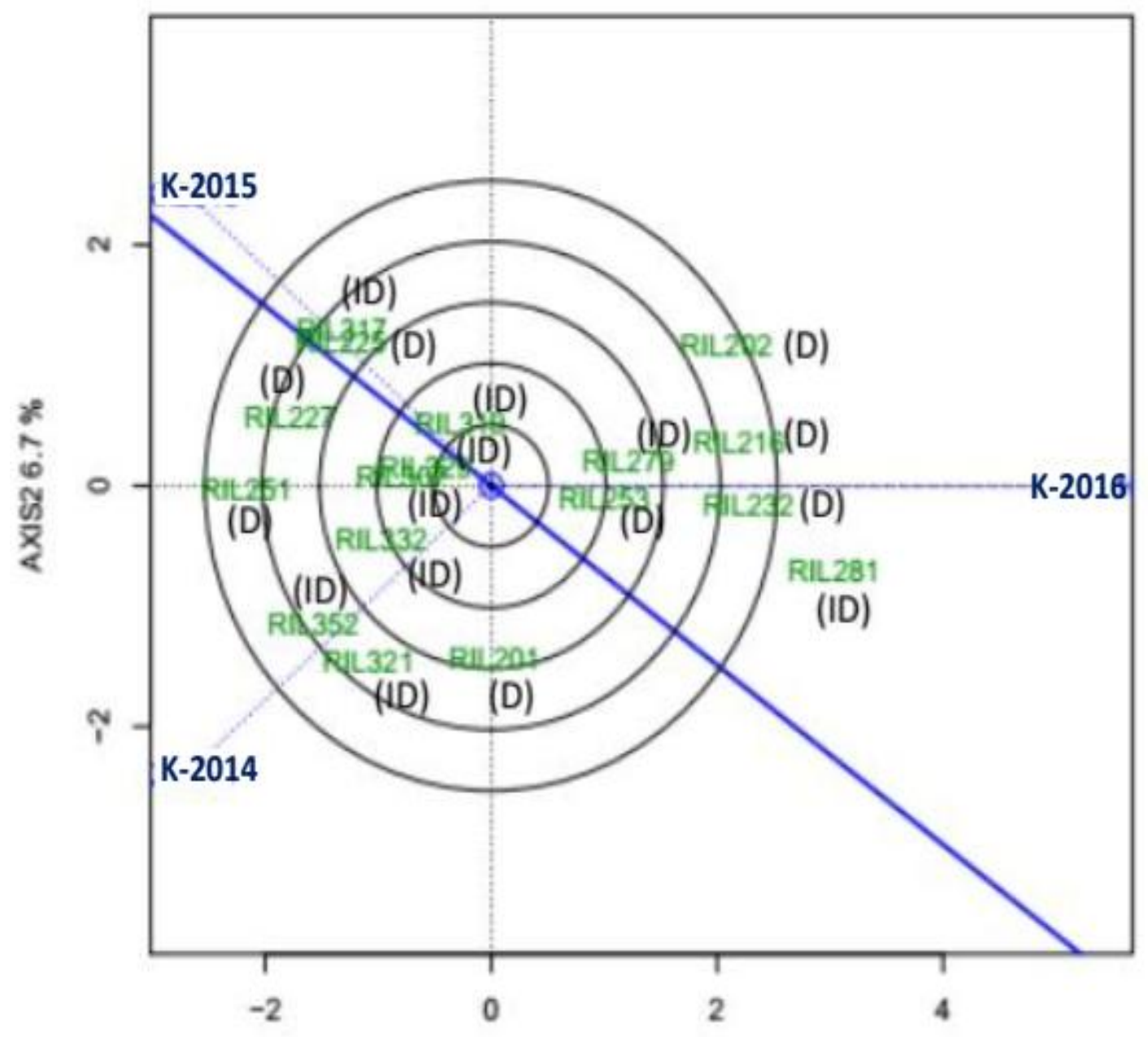

\begin{tabular}{|l|c|}
\hline RIL 201 & D \\
\hline RIL 202 & D \\
\hline RIL 216 & D \\
\hline RIL 225 & D \\
\hline RIL 227 & D \\
\hline RIL 232 & D \\
\hline RIL 251 & D \\
\hline RIL 253 & D \\
\hline RIL 279 & ID \\
\hline RIL 281 & ID \\
\hline RIL 307 & ID \\
\hline RIL 317 & ID \\
\hline RIL 319 & ID \\
\hline RIL 321 & ID \\
\hline RIL 329 & ID \\
\hline RIL 332 & ID \\
\hline RIL 352 & ID \\
\hline *D - Determinate \\
ID - Indeterminate \\
\hline
\end{tabular}

AXIS1 $93.3 \%$ 
Fig.2a Average Year Coordination (AYC) view of GGY bi-plot based on genotype-focused scaling for comparison of genotypes with the ideal genotype for seed yield plant $^{-1}$ in medium duration (51-60 days to flowering) RILs derived from HACPI 3

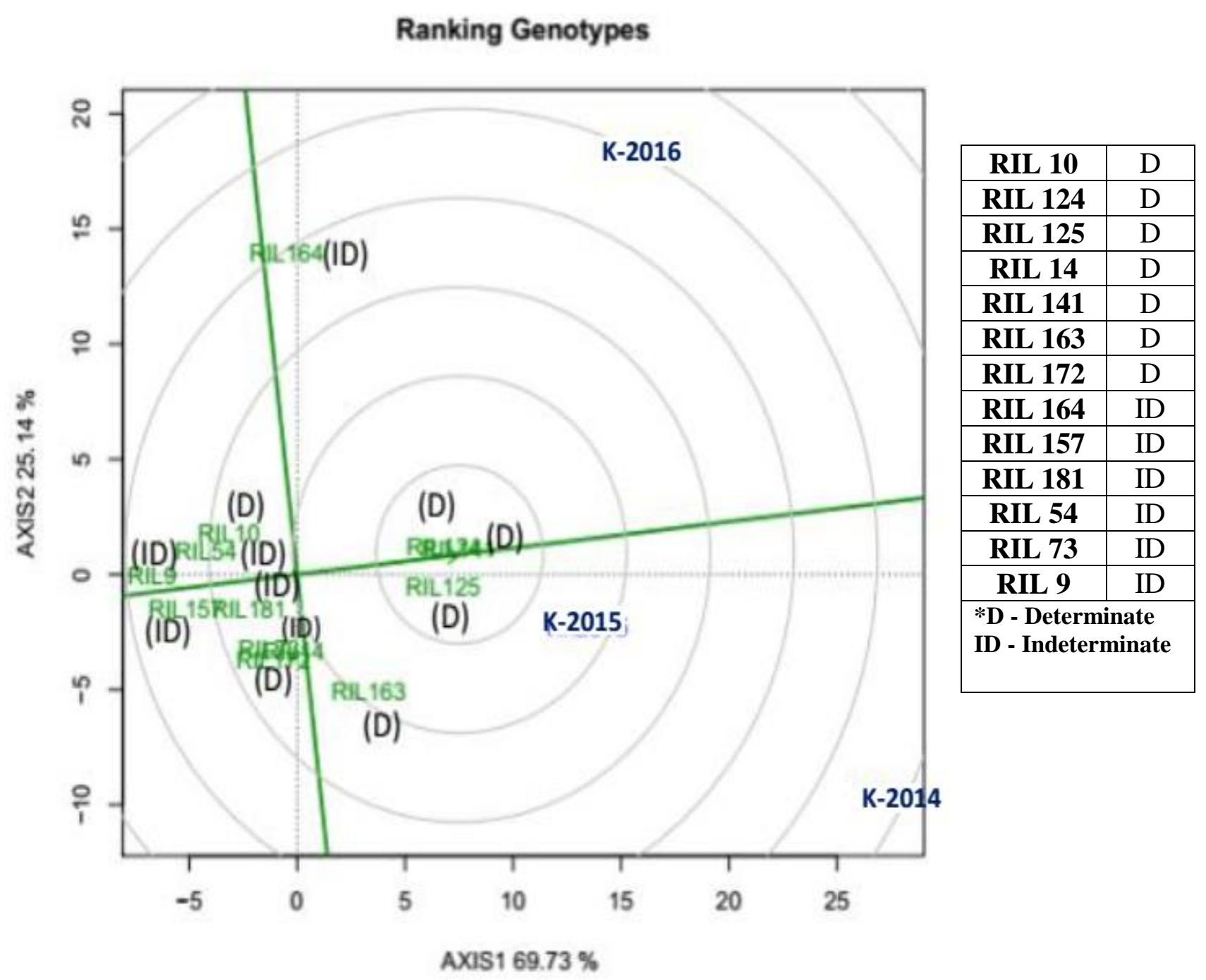


Fig.2b Average Year Coordination (AYC) view of GGY bi-plot based on genotype-focused scaling for comparison of genotypes with the ideal genotype for seed yield plant ${ }^{-1}$ in early duration ( $<50$ days to flowering) RILs derived from HACPI 6

\section{Ranking Genotypes}

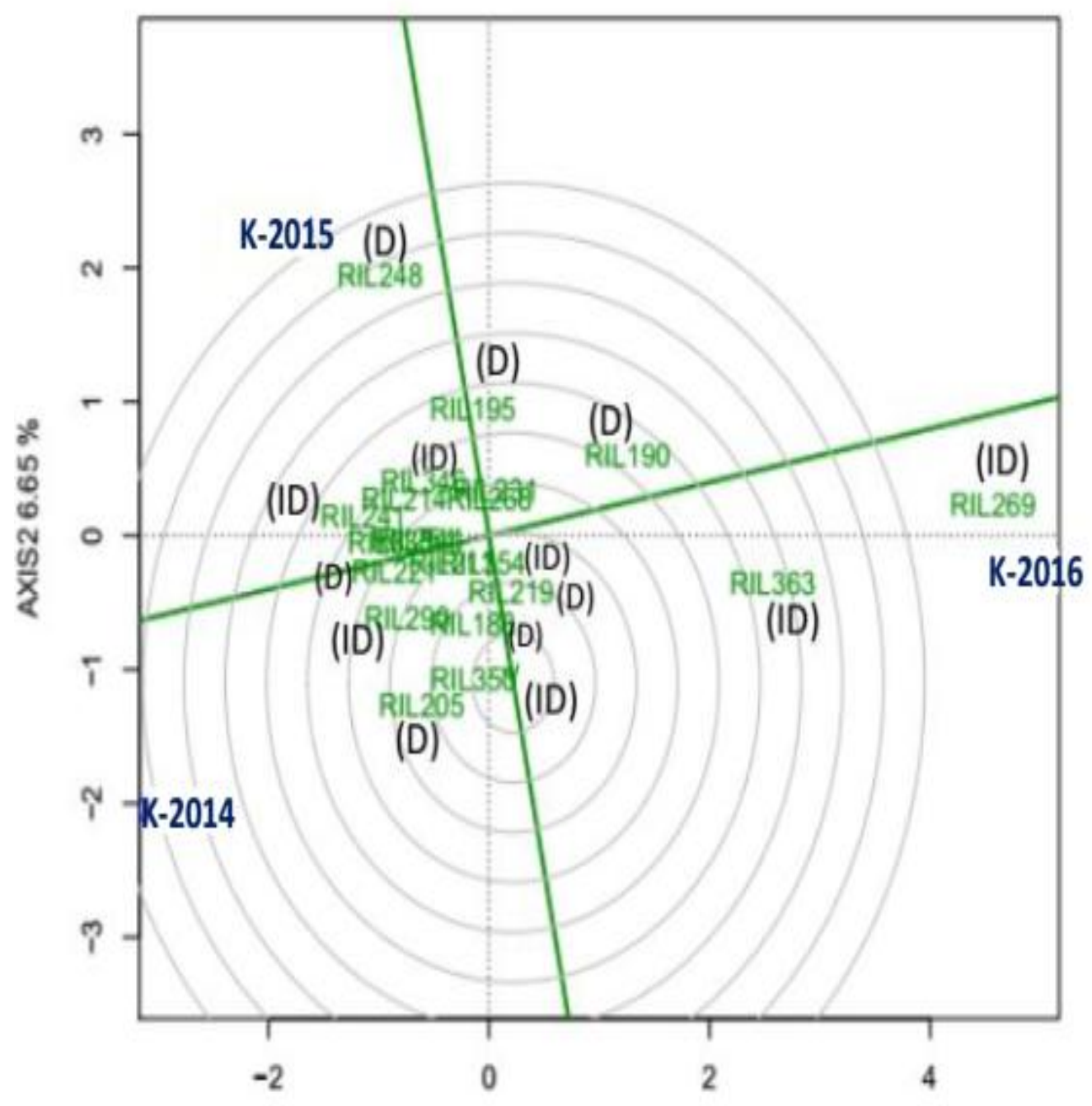

\begin{tabular}{|l|c|}
\hline RIL 188 & D \\
\hline RIL 190 & D \\
\hline RIL 195 & D \\
\hline RIL 205 & D \\
\hline RIL 211 & D \\
\hline RIL 214 & D \\
\hline RIL 219 & D \\
\hline RIL 221 & D \\
\hline RIL 231 & D \\
\hline RIL 248 & D \\
\hline RIL 254 & D \\
\hline RIL 241 & ID \\
\hline RIL 268 & ID \\
\hline RIL 269 & ID \\
\hline RIL 290 & ID \\
\hline RIL 335 & ID \\
\hline RIL 344 & ID \\
\hline RIL 346 & ID \\
\hline RIL 350 & ID \\
\hline RIL 354 & ID \\
\hline RIL 363 & ID \\
\hline *D - Determinate \\
ID - Indeterminate \\
\hline
\end{tabular}

AXIS1 $93.35 \%$ 
Fig.2c Average Year Coordination (AYC) view of GGY bi-plot based on genotype-focused scaling for comparison of genotypes with the ideal genotype for seed yield plant ${ }^{-1}$ in medium duration (51-60 days to flowering) RILs derived from HACPI 6

\section{Ranking Genotypes}

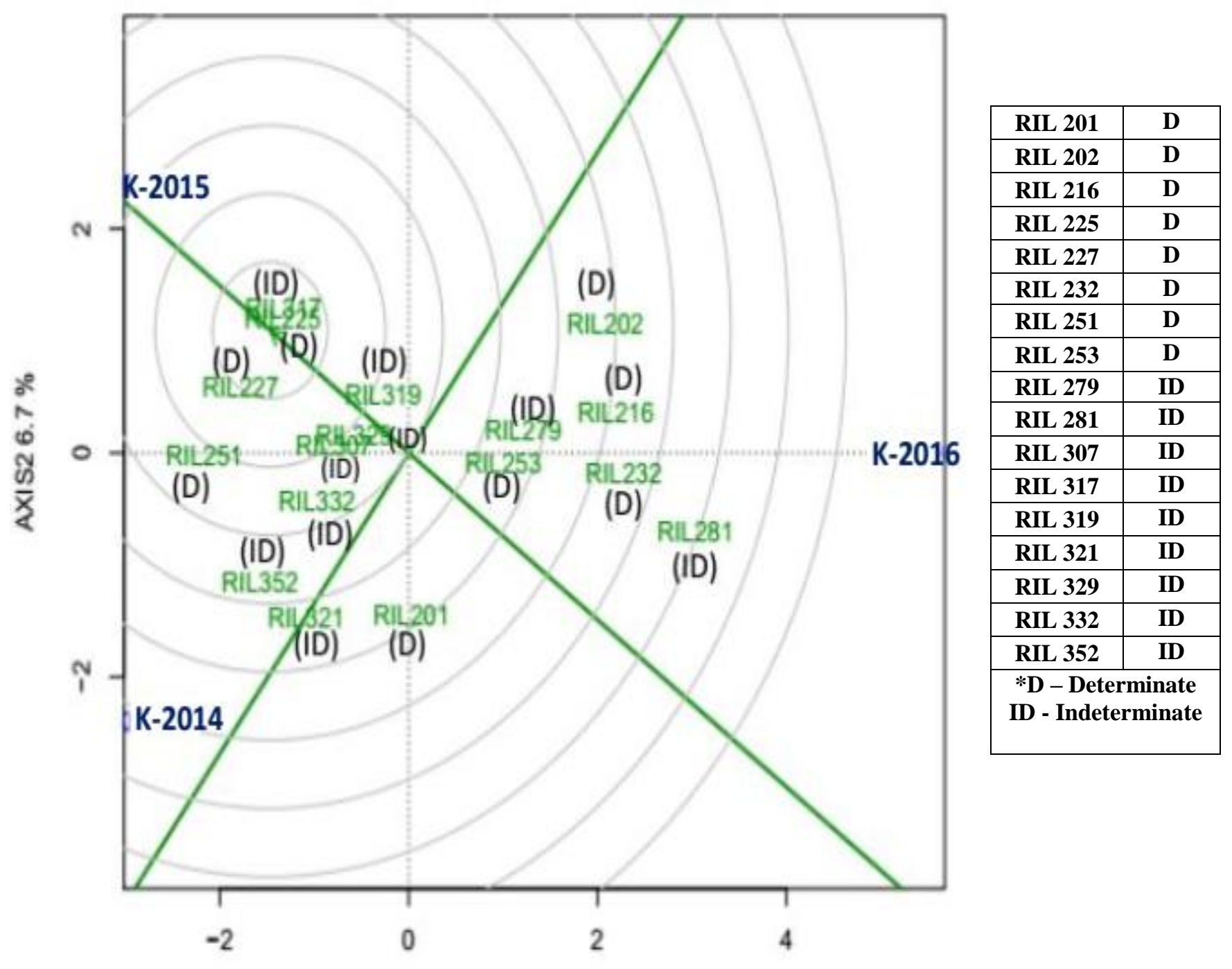

AXIS1 $93.3 \%$ 
Fig.3a Average Year Coordination (AYC) view of GGY bi-plot based on environment-focused scaling for the mean performance $v s$. stability for seed yield plant $^{-1}$ in medium duration (51-60 days to flowering) RILs derived from HACPI 3

Ranking biplot (Total $-94.88 \%$ )

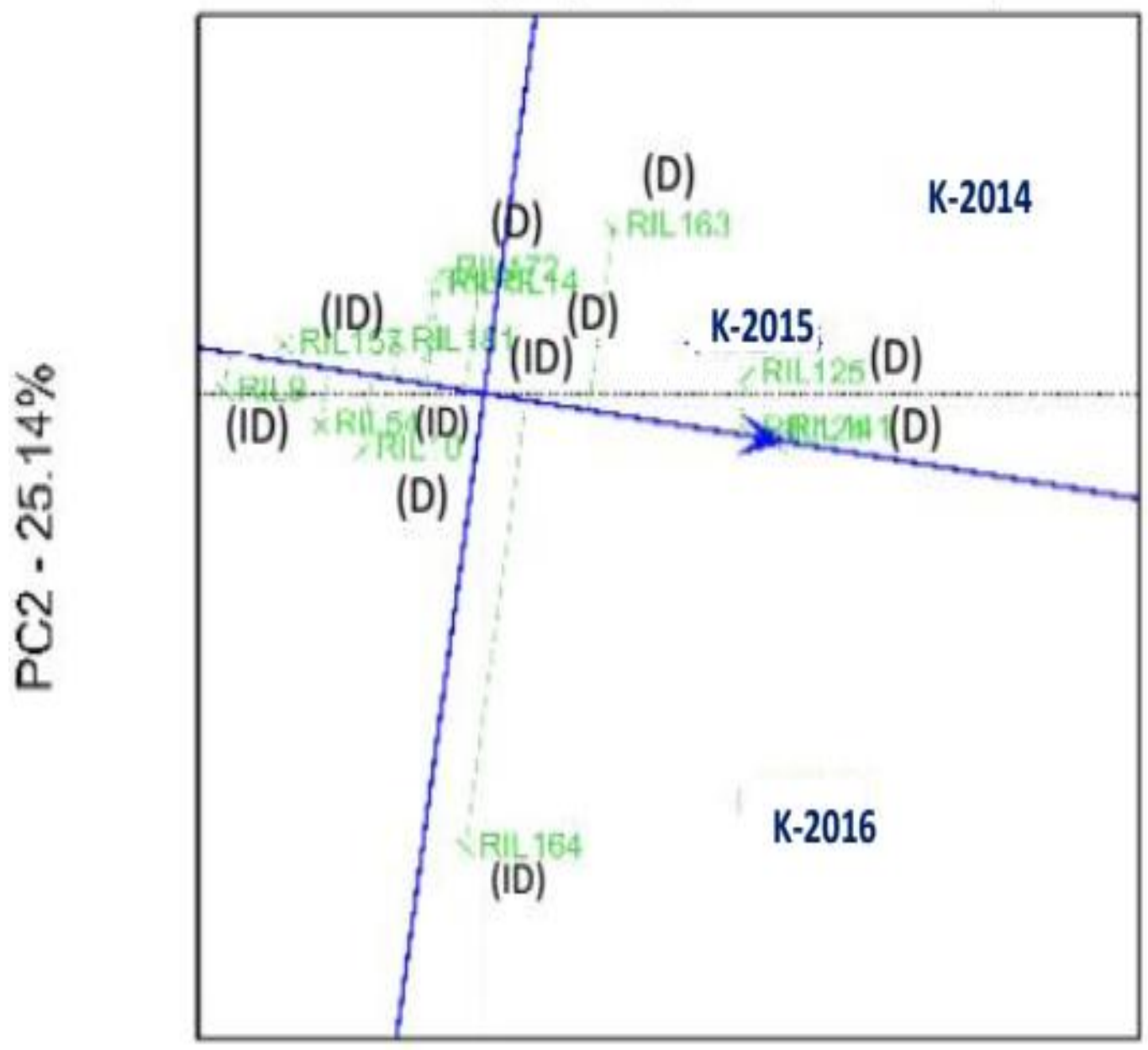

\begin{tabular}{|c|c|}
\hline RIL 10 & D \\
\hline RIL 124 & D \\
\hline RIL 125 & D \\
\hline RIL 14 & D \\
\hline RIL 141 & D \\
\hline RIL 163 & D \\
\hline RIL 172 & D \\
\hline RIL 164 & ID \\
\hline RIL 157 & ID \\
\hline RIL 181 & ID \\
\hline RIL 54 & ID \\
\hline RIL 73 & ID \\
\hline RIL 9 & ID \\
\hline *D - Determinate \\
ID - Indeterminate \\
\hline
\end{tabular}


Fig.3b Average Year Coordination (AYC) view of GGY bi-plot based on environment-focused scaling for the mean performance $v s$. stability for seed yield plant ${ }^{-1}$ in early duration $(<50$ days to flowering) RILs derived from HACPI 6

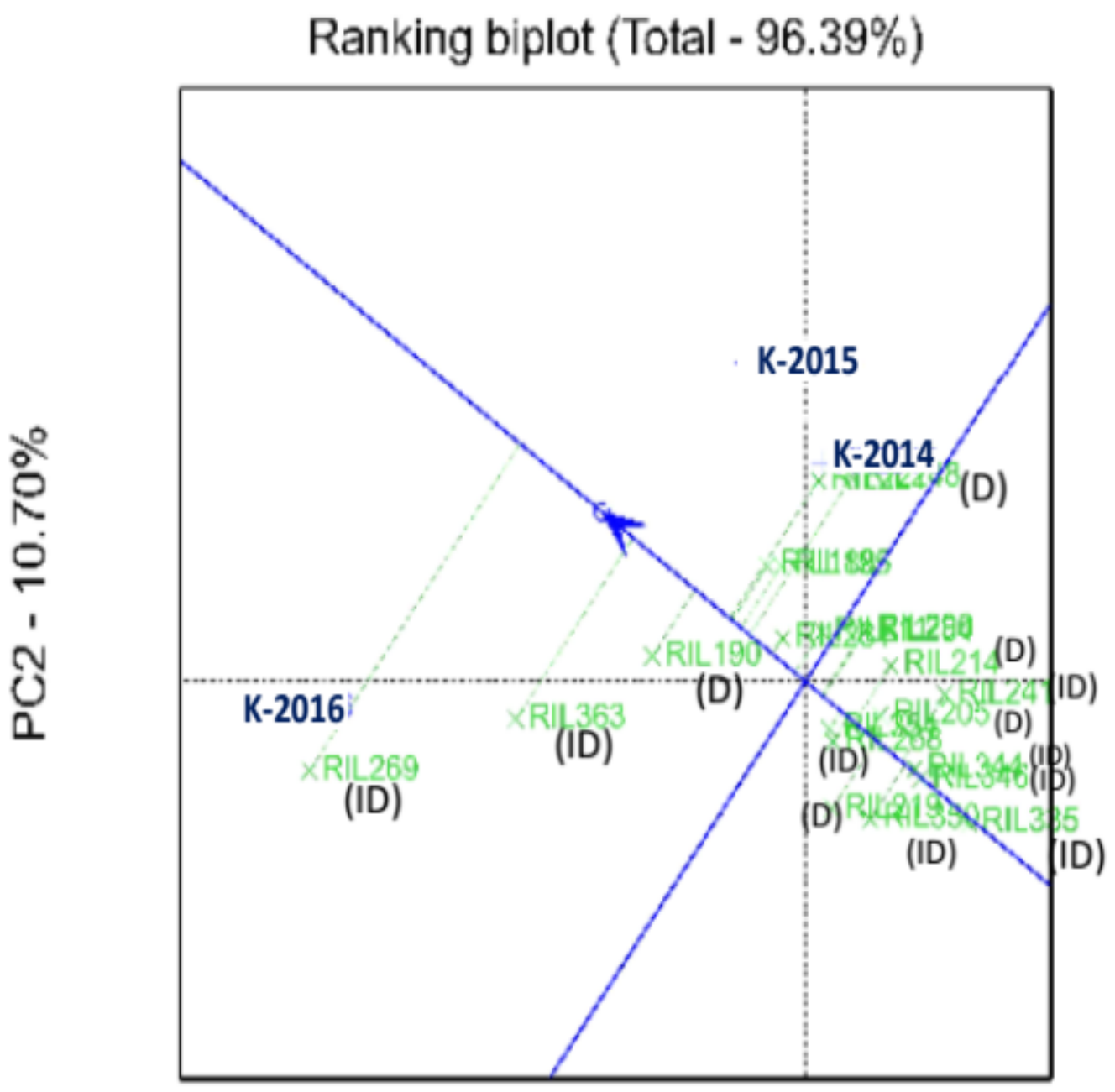

\begin{tabular}{|c|c|}
\hline RIL 188 & D \\
\hline RIL 190 & D \\
\hline RIL 195 & D \\
\hline RIL 205 & D \\
\hline RIL 211 & D \\
\hline RIL 214 & D \\
\hline RIL 219 & D \\
\hline RIL 221 & D \\
\hline RIL 231 & D \\
\hline RIL 248 & D \\
\hline RIL 254 & D \\
\hline RIL 241 & ID \\
\hline RIL 268 & ID \\
\hline RIL 269 & ID \\
\hline RIL 290 & ID \\
\hline RIL 335 & ID \\
\hline RIL 344 & ID \\
\hline RIL 346 & ID \\
\hline RIL 350 & ID \\
\hline RIL 354 & ID \\
\hline RIL 363 & ID \\
\hline *D - Determinate \\
ID - Indeterminate \\
\hline
\end{tabular}

PC1 $-85.69 \%$ 
Fig.3c Average Year Coordination (AYC) view of GGY bi-plot based on environment- focused scaling for the mean performance $v s$. stability for seed yield plant ${ }^{-1}$ in medium duration (51-60 days to flowering) RILs derived from HACPI 6

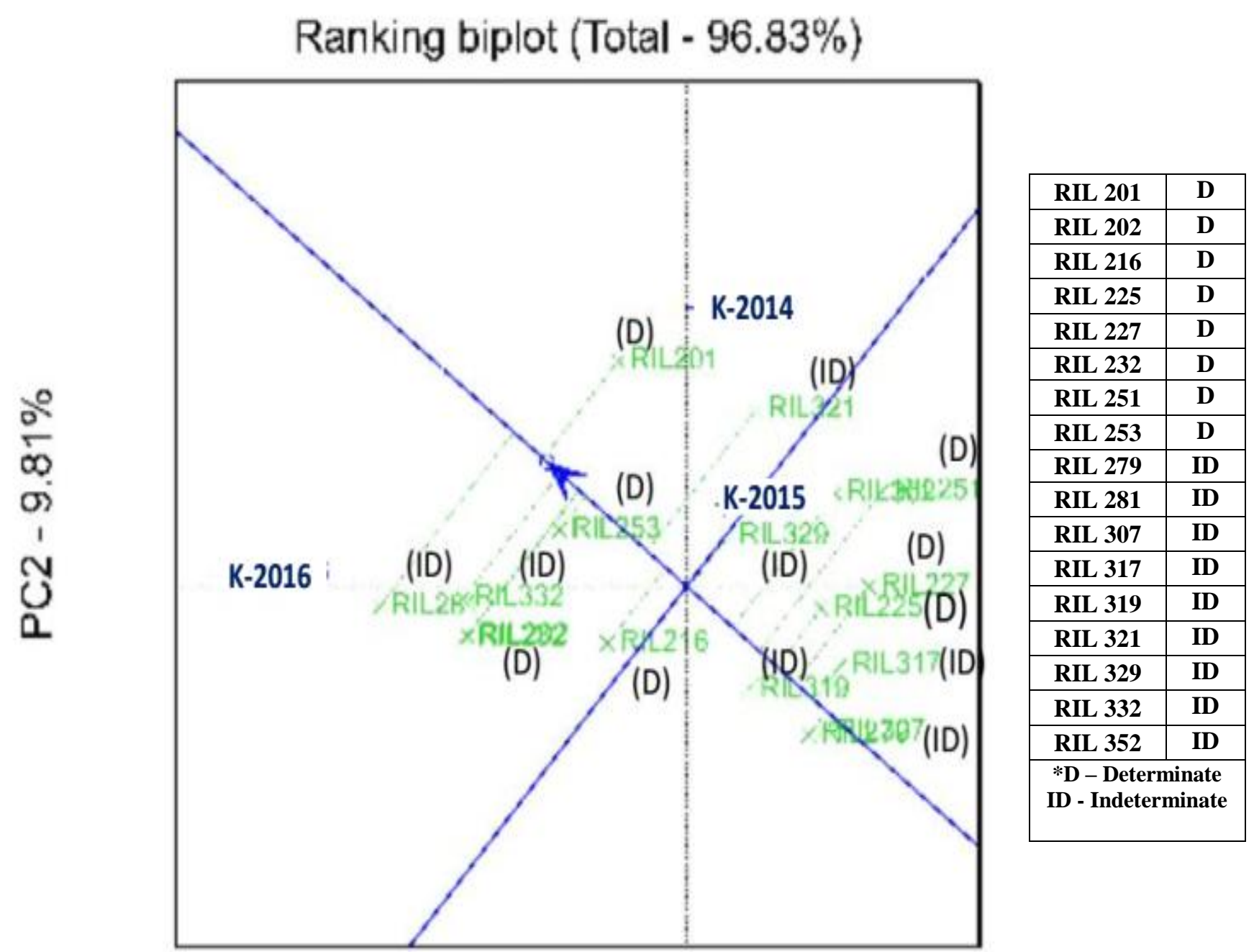


Fig.4a Polygon view of GGY bi-plot based on the symmetrical scaling for 'which-won-where' pattern of genotypes and years for seed yield plant $^{-1}$ in medium duration (51-60 days to flowering) RILs derived from HACPI 3

\section{Which Won Where/What}

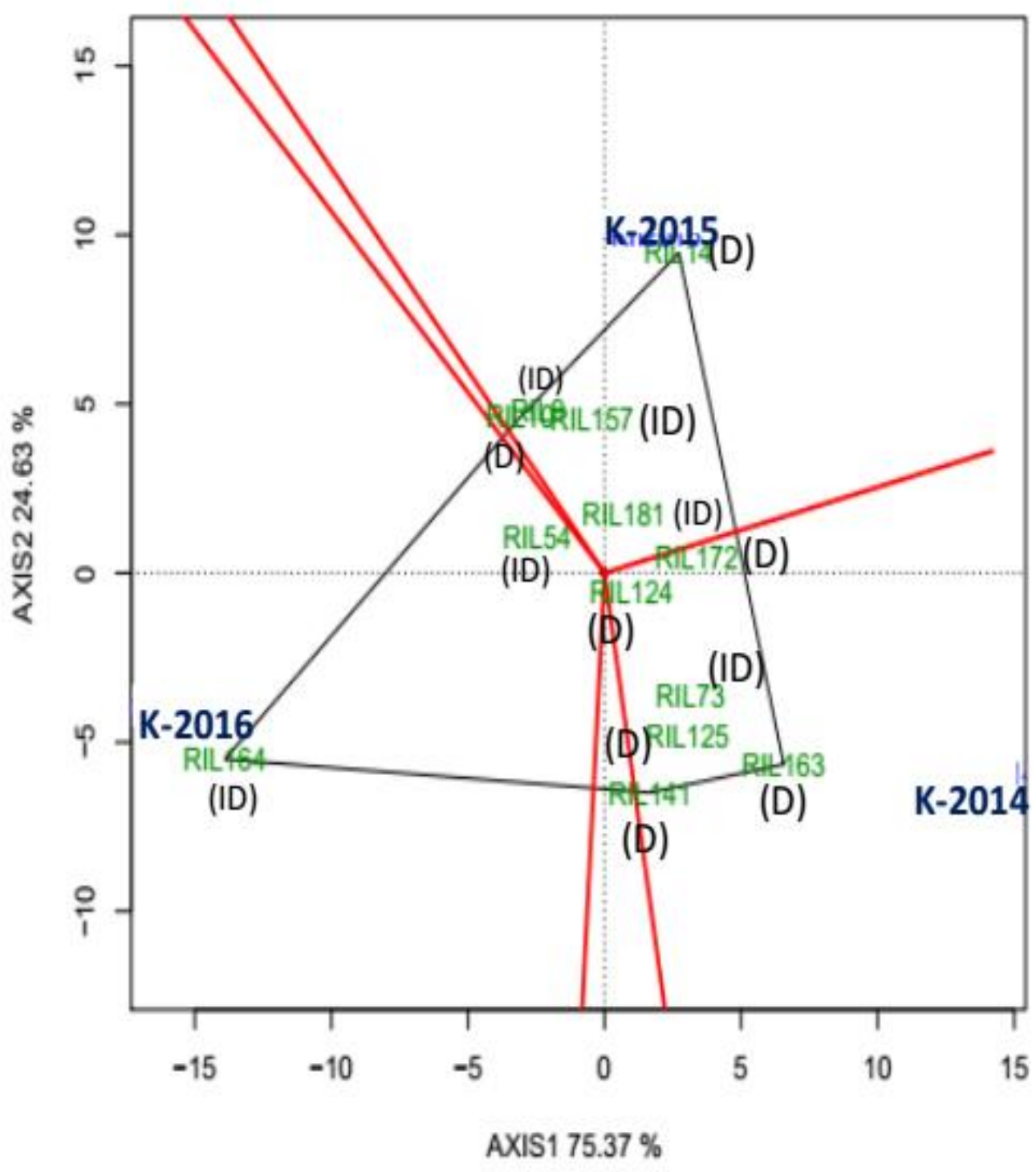

\begin{tabular}{|c|c|}
\hline RIL 10 & D \\
\hline RIL 124 & D \\
\hline RIL 125 & D \\
\hline RIL 14 & D \\
\hline RIL 141 & D \\
\hline RIL 163 & D \\
\hline RIL 172 & D \\
\hline RIL 164 & ID \\
\hline RIL 157 & ID \\
\hline RIL 181 & ID \\
\hline RIL 54 & ID \\
\hline RIL 73 & ID \\
\hline RIL 9 & ID \\
\hline *D - Determinate \\
ID - Indeterminate \\
\hline \multicolumn{2}{|l}{} \\
\hline
\end{tabular}

AXIS175.37\% 
Fig.4b Polygon view of GGY bi-plot based on the symmetrical scaling for 'which-wonwhere' pattern of genotypes and years for seed yield plant ${ }^{-1}$ flowering in early duration ( $<50$ days to flowering) RILs derived from HACPI 6

\section{Which Won Where/What}

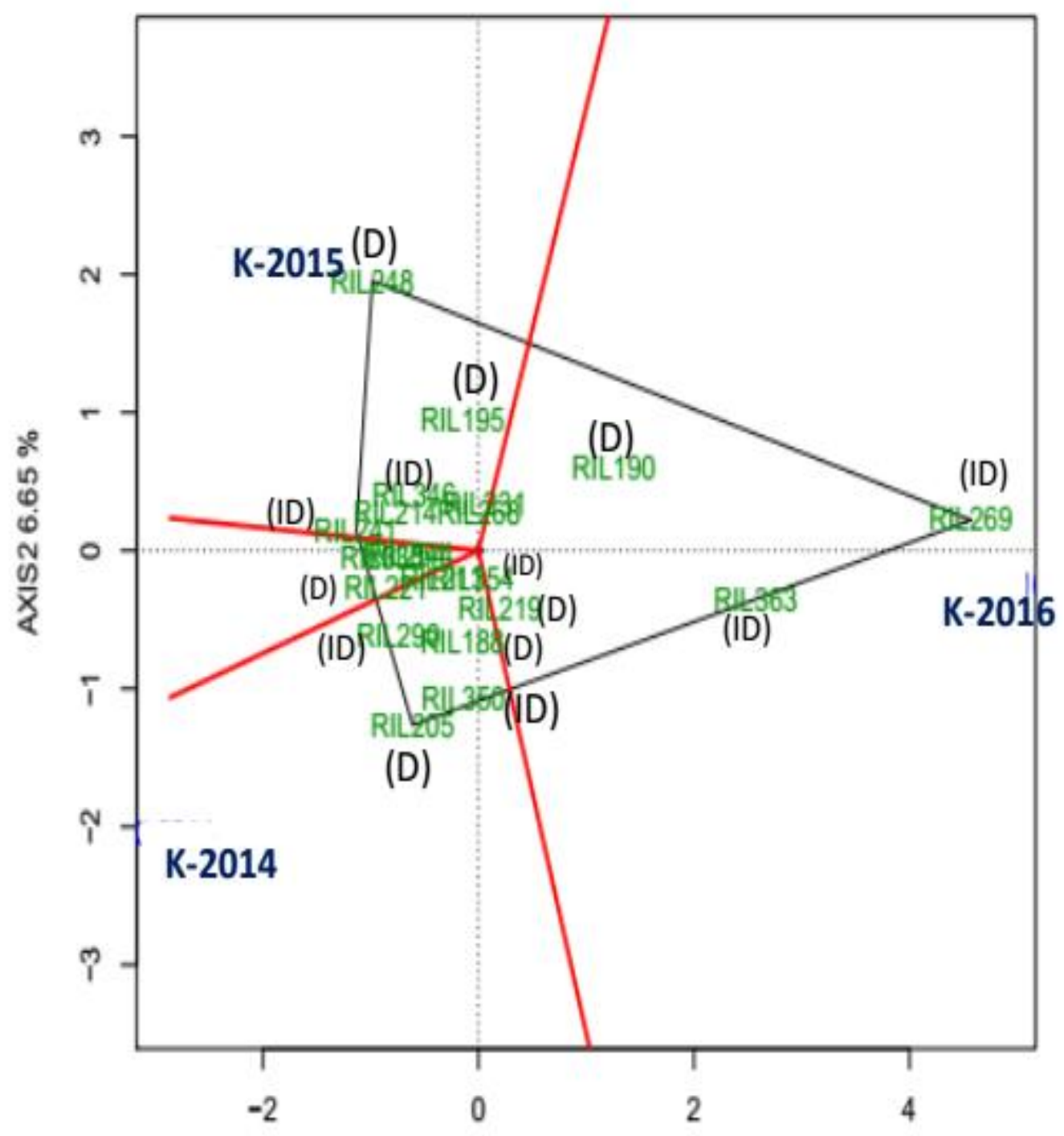

\begin{tabular}{|c|c|}
\hline RIL 188 & D \\
\hline RIL 190 & D \\
\hline RIL 195 & D \\
\hline RIL 205 & D \\
\hline RIL 211 & D \\
\hline RIL 214 & D \\
\hline RIL 219 & D \\
\hline RIL 221 & D \\
\hline RIL 231 & D \\
\hline RIL 248 & D \\
\hline RIL 254 & D \\
\hline RIL 241 & ID \\
\hline RIL 268 & ID \\
\hline RIL 269 & ID \\
\hline RIL 290 & ID \\
\hline RIL 335 & ID \\
\hline RIL 344 & ID \\
\hline RIL 346 & ID \\
\hline RIL 350 & ID \\
\hline RIL 354 & ID \\
\hline RIL 363 & ID \\
\hline *D - Determinate \\
ID - Indeterminate \\
\hline
\end{tabular}

AXIS1 $93.35 \%$ 
Fig.4c Polygon view of GGY bi-plot based on the symmetrical scaling for "which-wonwhere' pattern of genotypes and years for seed yield plant ${ }^{-1}$ in medium duration (5160 days to flowering) RILs derived from HACPI 6

\section{Which Won Where/What}

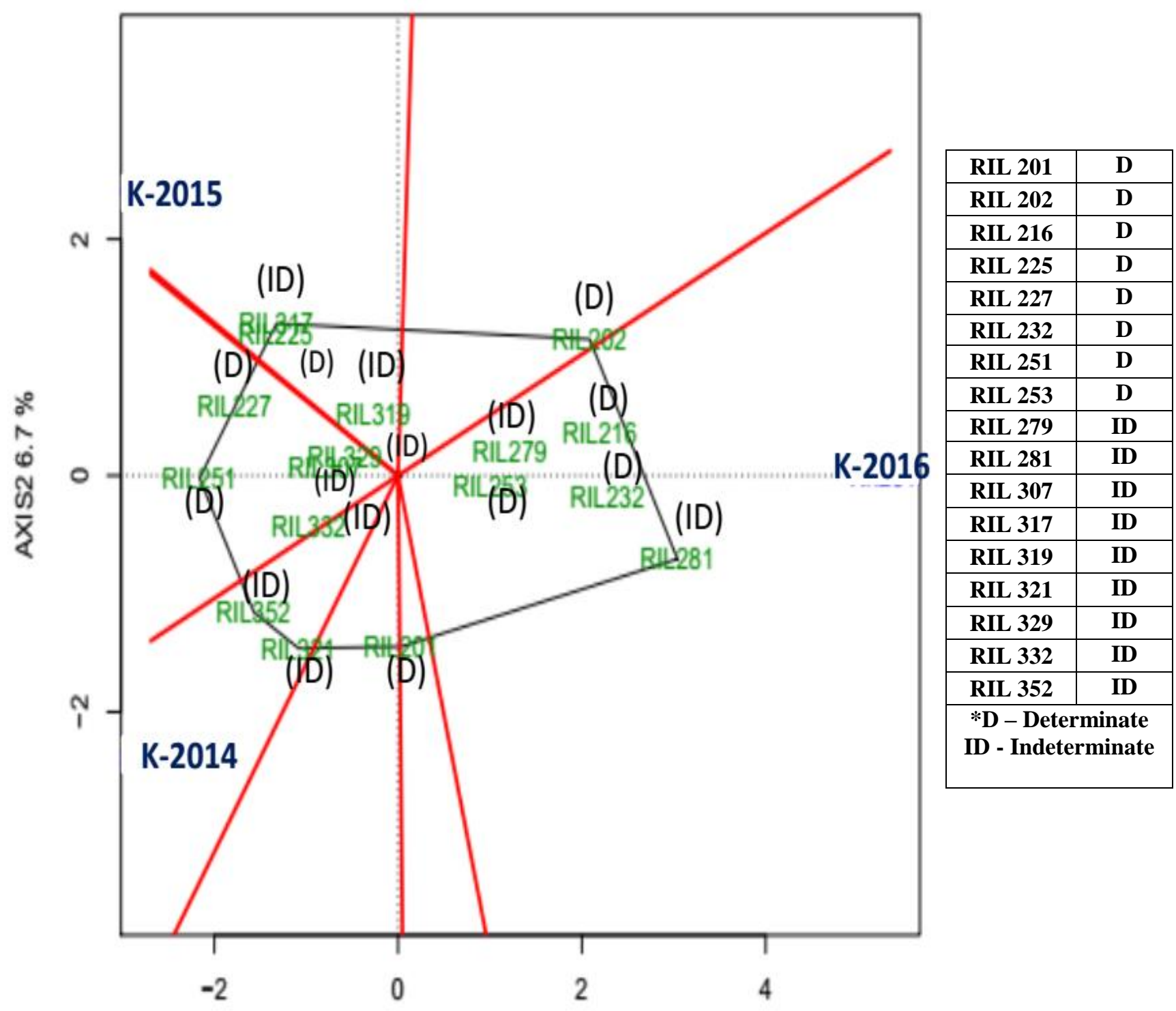

AXIS1 $93.3 \%$ 
The presence of positive correlation between test years suggests that same information about the genotypes could be obtained from fewer test years, and hence the potential to reduce the testing cost. Test years that are consistently non-discriminating (noninformative) provide little information on the performance of genotypes. A test year that has a smaller angle with AYC is more representative of test years. Test years that are both discriminating and representative are good test years for selecting stable genotypes. Discriminating but non-representative test years are useful for selecting year-specific genotypes. Discriminating but nonrepresentative test years are useful for culling unstable genotypes. Non-discriminating test years (those with very short vectors) are less useful because they hardly discriminate the genotypes. The genotypes located closer to the ideal genotypes are more desirable than others. The genotypes located near the biplot origin contribute little to both genotypes and GYI. The genotypes with longer vectors have large contributions to either G or GYI or both. Therefore, genotypes with the longest vectors are either the best or poorest or more unstable genotypes.

The year represented by $K$-2016 discriminated both early and medium duration RILs derived from HACPI 6 and medium duration RILs derived from HACPI 3 for seed yield plant ${ }^{-1}$ better than the ones represented by $K-2014$ and $K-2015$. On the other hand, the year represented by both $K$-2014 and $K$-2015 were comparable for their ability to discriminate HACPI6-derived early and medium duration RILs and HACPI 3-derived medium duration RILs for seed yield plant ${ }^{-1}$.

Shorter vector of $K$-2015 than those of $K$ 2014 and $K$-2016 suggested that environment represented by $K$-2015 least discriminated RILs than those represented by $K-2014$ and $K$-2016. The obtuse angles between the vectors of $K-2014$ and $K-2015 ; K-2015$ and $K$-2016; and $K$-2016 and $K$-2014 suggested negative relationship between environment represented by these pairs of test years. Further, it suggests that while one test year enhances the performance of RILs, others decrease their performance. The close angle of $K-2015$ vectors to AYC than those of $K$ 2014 and $K$-2016 indicated the environment represented by $K-2014$ and $K$-2016 effectively discriminated the RILs and $K-2015$ was more representative. Obtuse angle and hence strong negative correlation between the vectors of $K$ 2014, $K-2015$ and $K-2016 \quad$ suggest dissimilarity of these years for the expression of medium duration RILs derived from HACPI 3 for seed yield plant ${ }^{-1}$ (Fig. 1a).

The shorter vector of $K$-2015 than those of $K$ 2014 and $K$-2016 suggested the least discriminating ability of $K-2014$ and $K-2016$. The acute angle between the vectors of $K$ 2014 and $K$-2015, while the obtuse angles between the vectors of $K-2015$ and $K-2016$; $K-2014$ and $K$-2016 suggested similarity of the environments represented by $K-2015$ and $K-2016$, while dissimilarity of environments represented by $K-2014$ and $K-2016$. The longer and closer angle of vector of $K$-2016 to AYC than those of $K-2014$ and $K-2015$ suggested that $K-2016$ adequately discriminated the RILs and representative of the test years for seed yield plant ${ }^{-1}$. Acute angle indicated strong positive correlation between the vectors of $K-2014$ and $K-2015$ in early duration RILs derived from HACPI 6 (Fig. 1b).

The shorter vectors of $K-2014$ and $K-2015$ than that of $K-2016$ suggested better discriminating ability of $K$-2016 than $K$-2014 and $K$-2015. The obtuse angles suggested negative relationships between $K-2014$ and $K$ 2015; $K$-2015 and $K$-2016; and $K$-2014 and $K$-2016. The closer and longer angle of vectors of $K-2015$ to AEC than those of $K$ - 
2014 and $K$-2016 suggested $K$-2016 effectively discriminated the RILs and was more representative of the test years. Obtuse angle suggested strong negative correlation and hence dissimilarity between $K-2014, K$ 2015 in medium duration RILs derived from HACPI 6 (Fig. 1c).

\section{Genotype (represented by RIL) evaluation}

\section{Ranking RILs relative to ideal RIL}

An ideal genotype should have both high mean performance and high stability across years. An ideal genotype (located at the center of concentric circles) is the point on AYC in the GGY bi-plot in the positive direction and has a vector length equal to the longest vector of the genotypes on the positive side of AYC. Using the ideal genotype as the center, concentric circles are drawn to help visualize the distance between each genotype and ideal genotype. The genotypes located at the centre of concentric circles and very close to it are more desirable than others. While the points of most of the determinate RILs derived from HACPI3 located at the centre of concentric circle, those of indeterminate RILs located away from the centre of concentric circles. Thus, the determinate RIL 141, RIL 124 and RIL 125 could be regarded as most desirable from both performance and stability points of view than the other determinate RILs and all the indeterminate RILs for seed yield plant ${ }^{-1}$ in medium duration RILs derived from HACPI 3 (Fig. 2a).

In comparison with determinates, the early duration HACPI 6-derived indeterminate RIL 350 was adjudged as the ideal one as indicated by its location more nearer to the centre of the concentric circles than other indeterminate and determinate RILs. The determinate RIL 188 followed by RIL 205 and RIL 219, and indeterminate RIL 290 and RIL 354 were located relatively little away from the center of concentric circles suggesting that their performances were more towards ideal RIL from stability point of view (Fig. 2b).

The location of HACPI 6-derived medium duration determinate RIL 225 and indeterminate RIL 317 in the center of concentric circles indicated them as ideal RILs. The location of determinate RIL 227 and RIL 251, and indeterminate RIL 307, RIL 329 and RIL 319 little away from the center of concentric circles in GGY bi-plots suggested that they are more towards ideal RIL from both performance and stability point of view (Fig. 2c).

\section{Mean performance $v s$. stability patterns view of GGY bi-plot}

The mean performance and stability could be visualized through environment of RILs in relation to AYC view of GGY bi-plot based on year-focused scaling for the mean performance and stability of RILs. The single arrowed AYC points to higher mean performance of the genotypes across years (Yan, 2001). The RILs with their points located towards arrow of AYC are considered to exhibit high mean performance. On the contrary, the RILs with their points located opposite AYC arrow are considered to exhibit lower performance. Further, the relative lengths of projections of the RILs from AYC are indicative of their relative stability. The greater the absolute length of the projections of RILs, lower would be their stability (Yan and Kang, 2003).

The location of points of HACPI 3-derived medium duration determinate RIL 141, RIL 124 and RIL 125 towards AYC arrow suggested their better performance, while those of all other RILs were located opposite to AYC arrow suggested their poor performance. The length of the projections of 
determinate RIL 141 and RIL 124 from AEC were least followed by indeterminate RIL 9, RIL 157, RIL 54 and RIL 181 suggested their better stability and performance for seed yield plant $^{-1}$ (Fig. 3a).

The location of HACPI 6-derived early duration indeterminate RIL 269 towards AYC arrow suggested its better performance, while those of all other indeterminate and determinate RILs opposite to AYC arrow suggested their poor performance. The least lengths of the projections of indeterminate RIL 268 and RIL 354, RIL 350, RIL 344 and RIL 346; determinate RIL 219 and RIL 190 from AEC suggested their better stability for seed yield plant ${ }^{-1}$. These results indicate comparable performance and stability of early duration determinate or indeterminate HACPI 6-derived RILs (Fig. 3b).

The locations of medium duration HACPI 6derived determinate RIL 201 and indeterminate RIL 281 towards AYC arrow suggested their better performance, while those of all other RILs opposite to AYC arrow suggested their poor performance. The least lengths of the projections of determinate RIL 253 and indeterminate RIL 319 and RIL 307 from AYC followed by determinate RIL 216, RIL 225 and RIL 217; indeterminate RIL 317, RIL 329 and RIL 352 suggested any perceptible trend in favor of determinates or indeterminates RILs with respect to their stability and performance (Fig. 3c).

\section{'Which-won-where' pattern}

One of the features of GGY bi-plot is its ability to display 'which-won-where' pattern of a RILs. This feature is shown by polygon view of the GGY bi-plot. A polygon is drawn on RILs that are farthest from the bi-plot origin so that all other RILs fall within the polygon. The perpendicular lines starting from GGY bi-plot origin are drawn to each side of the polygon. The perpendicular lines are equality lines between adjacent RILs on the polygon. The RILs located on the vertices of the polygon perform either the best or poorest in one or more years (Yan et al., 2000). The equality lines divide the bi-plot into sectors. The vertex RILs in each sector is the winning RILs at environments whose markers (point) fall into the respective sector (Yan et al., 2000). Years within the same sector share the same winning RILs, and years in different sectors have different winning RILs, thus polygon view of a GGY bi-plot indicates presence or absence of crossover GYI (Yan and Rajcan, 2002).

The medium duration HACPI 3 derived determinate RIL 141 and RIL 163 were the winner in $K$-2014; determinate RIL 14 was the winner in $K$-2015 and indeterminate RIL 164 was the winner in $K$-2016 for seed yield plant $^{-1}$ (Fig. 4a). The determinate RIL 205, RIL 248 and indeterminate RIL 241, RIL 335 and RIL 269 were positioned at the vertices of the polygon of GGY bi-plot. The early duration HACPI 6-derived determinate RIL 205 and indeterminate RIL 335 were the winners in $K$-2014; determinate RIL 241 and RIL 248 were the winners in $K-2015$ and determinate RIL 269 was the winner in $K$ 2016 (Fig. 4b). Medium duration HACPI 6 derived RILs determinate RIL 201 and RIL 251 and indeterminate RIL 321 and RIL 352 were the winners in $K$-2014; determinate RIL 225 and indeterminate RIL 317 were the winners in $K$-2015; determinate RIL 202 and indeterminate RIL 281 were the winners in $K$ 2016 (Fig. 4c). Thus, different RILs were the winners in different years without any definite trend in favor of determinate and indeterminate RILs irrespective of their maturity groups.

The present study indicated that by and large determinate and indeterminate RILs are comparable for stability of seed yield plant ${ }^{-1}$ 
especially in early to medium maturity group. To the author's knowledge, the present study is first of its kind to compare the seed yield stability of a large number of determinate and indeterminate RILs belonging to different maturity groups. Thus, the results of the present study provide adequate evidence and hence support to breed early to medium duration determinate dolichos bean varieties with performance stability comparable to indeterminate varieties.

\section{References}

Ayyangar, G. N. R. and Nambiar, K. K. K. 1935. Studied in Dolichos lablab (Roxb.) (L.). The Indian field and garden bean. Proc. Indian Acad. Sci., 1(12): 857-867.

Byregowda, M., Gireesh, G., Ramesh, S., Mahadevu, P. and Keerthi, C. M. 2015. Descriptors of Dolichos bean (Lablab purpureus L.). J. Food Legumes, 28(3): 203-214.

Caligari, P. D. F and Mather, K. 1975. Genotype-environment interaction III. Interaction in Drosophila melanogaster. Proc. Royal Soc. London, 191:387-411.

Choudhury, A. R., Ali, M. and Quadri, M. A. 1989. Aspects of pollination and floral biology of lablab bean (Lablab purpureus L. Sweet). Japanese Soc. Hort. Sci. J., 58(3): 665-671.

Farshadfar, E., 2011, Chromosomal localization of the genes controlling adaptation in Agropyron elongatum using AMMI-based simultaneous selection index of yield and stability. Int. J. Plant Breed., 5(2): 80-83.

Gauch, H. G. and Zobel, F. W. 1988. Predictive and postdictive success of statistical analysis of yield trials. Theor. Appl. Genet., 76:1-10.

Girish, G. and Byregowda, M. 2009. Inheritance of qualitative characters in Dolichos bean Lablab purpureus L.
Sweet. Environ. Ecol., 27 (2): 571-580.

Harland, S. C. 1920. Inheritance in Dolichos lablab (L.). J. Genetics, 10: 219-226.

Mahadevu, P. and Byregowda, M. 2005. Genetic improvement of Dolichos bean (Lablab purpureus L.) through the use of exotic and indigenous germplasm. Indian J. Plant Genet. Resour., 18: 1-5.

Keerthi, C. M., Ramesh, S., Byregowda, M., Rao, A. M., Rajendra Prasad, B. S. and Vaijayanthi, P. V. 2014a. Genetics of growth habit and photoperiodic response to flowering time in dolichos bean (Lablab purpureus L. Sweet). J. Genet., 93: 203-206.

Keerthi, C. M., Ramesh, S., Byregowda, M., Mohan Rao, A., Marry Reena, G. A. and Chandrakant, N. 2014b. Performance stability of photoperiod sensitive vs. insensitive dolichos bean (Lablab purpureus L.) cultivars under delayed sowing conditions. Australian J. Crop Sci., 8(12): 1658-1662.

Kukade, S. A. and Tidke, J. A. 2014. Reproductive biology of Dolichos lablab L. (Fabaceae). Indian. J. Pl. Sci., 3(2): 22-25.

Laxmi, K., Vaijayanthi, P. V., Keerthi, C. M., Shivakumar, M. S., Ramesh, S. and Mohan Rao, A. 2016. Genotypedependent photoperiod-induced sensitivity to flowering time in dolichos bean (Lablab purpureus L. Sweet var. Lignosus). Bangladesh J. Bot., 45(3): 471-476.

Ludlow, M. M. and Muchow, R. C. 1990. A critical evaluation of traits for improving crop yields in water limited environments. Adv. Agron., 43: 107153.

Purchase, J. L., Hatting, H. and Van deventer, C. S. 2000. Genotype by environment interaction of winter wheat in South Africa: II. Stability analysis of yield performance. South African J. Plant 
Soil, 17:101-107.

Ramesh, S. and Byregowda, M. 2016. Dolichos bean (Lablab purpureus L. Sweet, var. Lignosus) genetics and breeding-present status and future prospects. Mysore J. Agric. Sci., 50(3): 481-500.

Segherloo, A. E., Sayyed, H. S., Dehghani, H. And Kamran, M. 2010. Screening of superior chickpea genotypes for various environments of Iran using genotype plus genotype by environment bi-plot analysis. J. Plant Breed. Crop Sci., 2(9): 286-292.

Shivashankar, G. and Kulkarni, R. S. 1989. Field bean [Dolichos lablab (L.)], var. lignosus Prain. Indian Hort., 34: 24-27.

Vita, P. D., Mastrangeola, A. M., Matteua, L., Mazzucotelliba, Virzi, N., Palumboc, M., Stortod, F., Rizzab and Cattielli, L. 2010. Genetic improvement effects on yield stability in durum wheat genotypes grown in Italy. Field Crops
Res., 119: 68-77.

Yan, W. 2001. GGE biplot- A window application for graphical analysis of multi-environment trial data and other types of two-way data. Agron. J., 93: 1111-1118.

Yan, W. and Rajcan, I. 2002. Biplot analysis of test sites and trait relations of soybean in Ontario. Crop Sci., 42: 1120.

Yan, W. and Tinker, N. A. 2006. Biplot analysis of multi-environment trial data: Principles and applications. Canadian J. Plant Sci., 86: 623-645.

Yan, W. and Kang, M. S. 2003. GGE biplot analysis: A graphical tool for breeders, geneticists and agronomists. CRC Press, Boca Raton, F. L.

Yan, W., Hunt, L. A., Sheng, Q. and Sziavnics, Z. 2000. Cultivar evaluation and mega environment investigation based on GGE biplot. Crop Sci., 40: 597-605.

\section{How to cite this article:}

Chandrakant, H.R. Uday Kumar, S. Ramesh, C.M. Keerthi, A. Mohan Rao, M. Byregowda and Suresh. 2018. Comparative Seed Yield Stability of Determinate and Indeterminate RILs of Dolichos Bean (Lablab purpureus L. Sweet) var. lignosus. Int.J.Curr.Microbiol.App.Sci. 7(01): 3269-3295. doi: https://doi.org/10.20546/ijcmas.2018.701.391 